\title{
Position Paper on Practicable Performance Criteria for the Removal Efficiency of Volatile Radionuclides
}

R. T. Jubin

N. R. Soelberg

D. M. Strachan

G. Ilas

March 2012

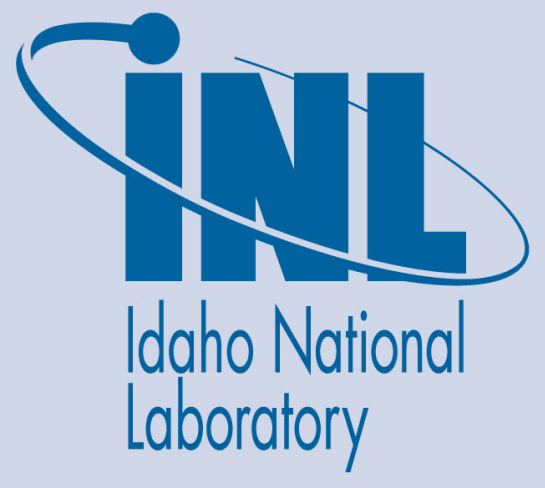

The INL is a U.S. Department of Energy National Laboratory operated by Battelle Energy Alliance 
INL/EXT-12-25410

FCRD-SWF-2012-000091

\title{
Position Paper on Practicable Performance Criteria for the Removal Efficiency of Volatile Radionuclides
}

\author{
R. T. Jubin ${ }^{1}$ \\ N. R. Soelberg \\ D. M. Strachan ${ }^{2}$ \\ G. Ilas ${ }^{1}$ \\ ${ }^{1}$ Oak Ridge National Laboratory \\ ${ }^{2}$ Pacific Northwest National Laboratory
}

March 2012

Idaho National Laboratory

Fuel Cycle Research \& Development Idaho Falls, Idaho 83415

http://www.inl.gov

Prepared for the

U.S. Department of Energy

Office of Nuclear Energy

Under DOE Idaho Operations Office

Contract DE-AC07-05ID14517 


\section{DISCLAIMER}

This information was prepared as an account of work sponsored by an agency of the U.S. Government. Neither the U.S. Government nor any agency thereof, nor any of their employees, makes any warranty, expressed or implied, or assumes any legal liability or responsibility for the accuracy, completeness, or usefulness, of any information, apparatus, product, or process disclosed, or represents that its use would not infringe privately owned rights. References herein to any specific commercial product, process, or service by trade name, trade mark, manufacturer, or otherwise, does not necessarily constitute or imply its endorsement, recommendation, or favoring by the U.S. Government or any agency thereof. The views and opinions of authors expressed herein do not necessarily state or reflect those of the U.S. Government or any agency thereof. 


\section{ACKNOWLEDGEMENTS}

We would like to thank Barry Spencer (ORNL) and D. Haefner (INL) for peer reviewing the report, Amy Harkey (ORNL) for her efforts to edit this document, and Kathy Jones (ORNL) for her efforts in formatting.

Prepared by Oak Ridge National Laboratory, P.O. Box 2008, Oak Ridge, Tennessee 37831-6285, managed by UT-Battelle, LLC, for the U.S. Department of Energy under contract DE-AC05-00OR22725.

This work was supported by the U.S. Department of Energy, Office of Nuclear Energy, under DOE Idaho Operations Office Contract DE-AC07-05ID14517.

Pacific Northwest National Laboratory is operated by Battelle for the U.S. Department of Energy under contract DE-AC06-76RLO1830. 



\section{SUMMARY}

As a result of fuel reprocessing, volatile radionuclides may be released from the facility stack if no processes are put in place to remove them. The radionuclides of concern in this document are ${ }^{3} \mathrm{H},{ }^{14} \mathrm{C}$, ${ }^{85} \mathrm{Kr}$, and ${ }^{129} \mathrm{I}$. The question we attempted to answer is how efficient must this removal process be for each of these radionuclides? To answer this question, we examined the three regulations that may impact the degree to which these radionuclides must be reduced before process gases can be released from the facility. These regulations are 40 CFR 61 (EPA 2010a), 40 CFR 190 (EPA 2010b), and 10 CFR 20 (NRC 2012). These regulations apply to the total radionuclide release and to a particular organ - the thyroid. Because these doses can be divided differently among all the radionuclides and even within the four radionuclides in question, we provided several cases. We first looked at the inventories for these radionuclides for three fuel types (PWR UOX, PWR MOX, and AHTGR), several burn-up values, and time out of reactor extending to $200 \mathrm{y}$. We calculated doses to the maximum exposed individual (MEI) with the EPA code CAP-88 (Rosnick 1992). Finally, we looked at two dose cases. Allocating all of the allowable dose to be used by the volatile radionuclides is one case but perhaps is unrealistic. In lieu of this, we arbitrarily selected a value of $10 \%$ of the allowable dose to be assigned to the volatile radionuclides. We calculated the required decontamination factors (DFs) for both of these cases, including the case for the thyroid dose for which ${ }^{14} \mathrm{C}$ and ${ }^{129} \mathrm{I}$ were the main contributors. With respect to ${ }^{129} \mathrm{I}$ doses, we found that the highest dose was calculated with iodine as a fine particulate. The dose scaled as the fraction of the total ${ }^{129} \mathrm{I}$ that was particulate. Therefore, we assumed for all our calculations that $100 \%$ of the ${ }^{129}$ I was particulate and allow the user of the results given here to scale our calculated doses to their needs.

To summarize the data given in this paper, we found that the principal isotopes of concern are ${ }^{3} \mathrm{H}$ and ${ }^{129} \mathrm{I}$, the latter requiring the highest DFs. The maximum DF calculated for ${ }^{129} \mathrm{I}$ was 8000 . The required DF for ${ }^{3} \mathrm{H}$ could be as high as 720 . The DF, depending fuel age, for ${ }^{85} \mathrm{Kr}$ could be up to $\sim 60$. The DF for ${ }^{14} \mathrm{C}$ could be as high as 30 . These DFs are within the range of DFs that are reported for the capture technologies for the volatile radionuclides. Achieving the required iodine and tritium DFs will be the more challenging. 



\section{CONTENTS}

ACKNOWLEDGEMENTS

SUMMARY $\mathrm{v}$

FIGURES ix

TABLES xi

ACRONYMS xiii

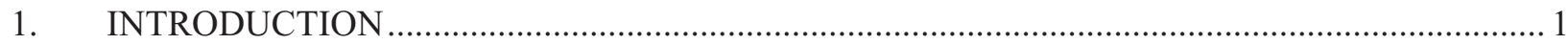

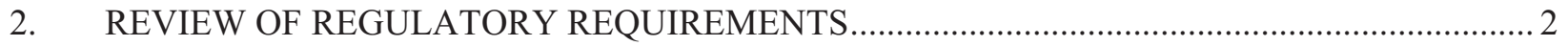

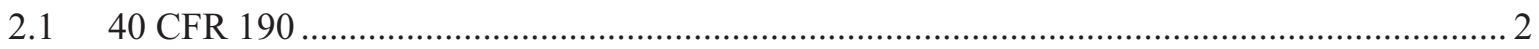

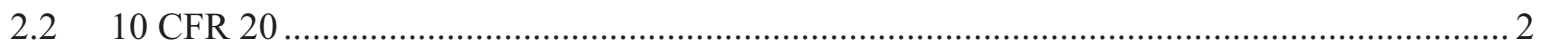

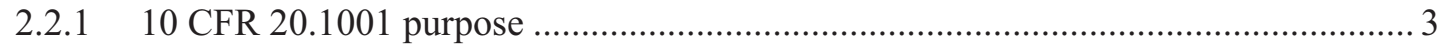

2.2.2 10 CFR 20.1302 compliance with dose limits for individual members of the

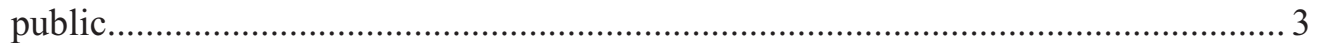

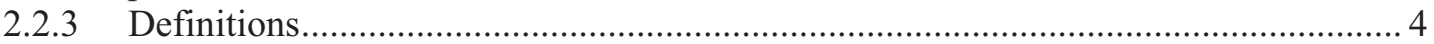

2.2.4 How compliance to 10 CFR 20 is addressed in this report ....................................... 4

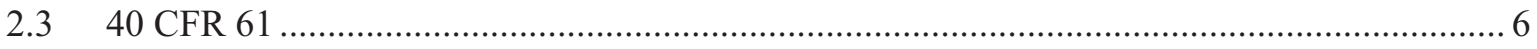

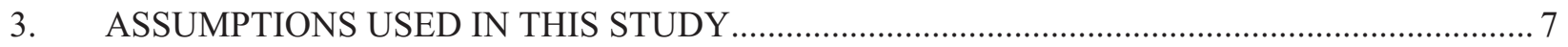

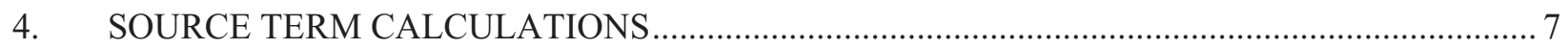

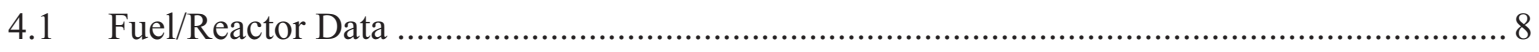

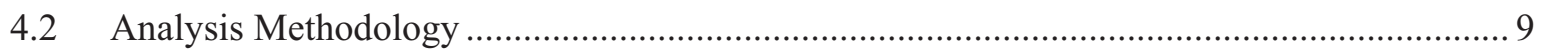

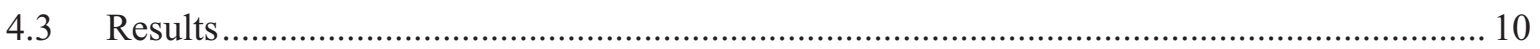

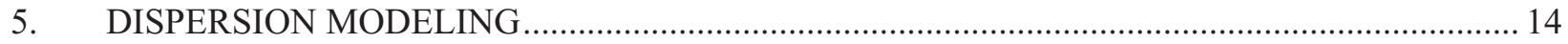

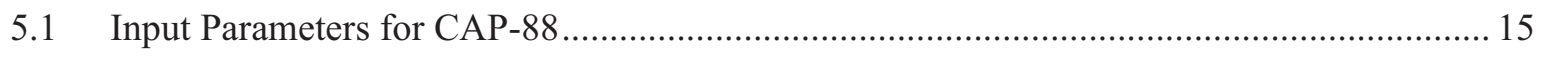

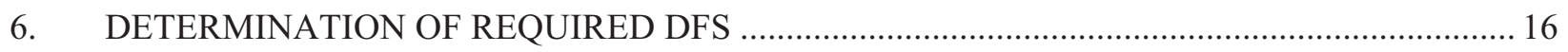

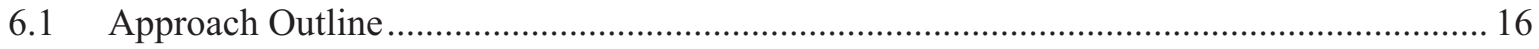

6.2 Example Case (PWR UOX - 30 GWD/MTIHM) ........................................................ 16

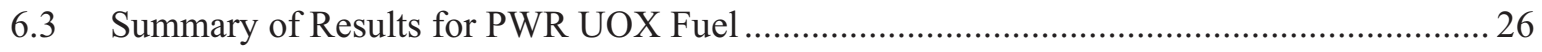

6.4 Summary of Results for PWR MOX Fuel …............................................................... 27

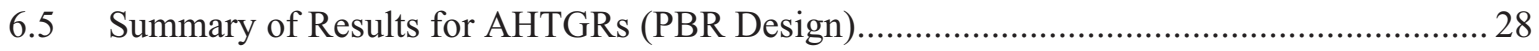

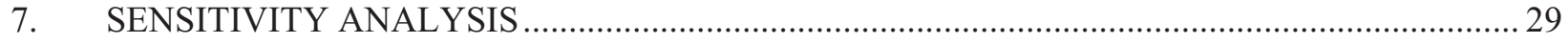

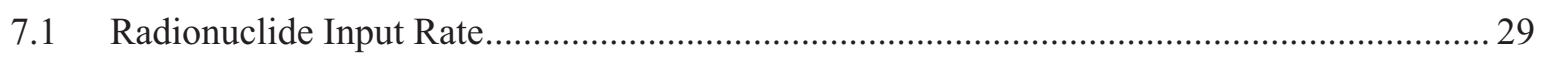

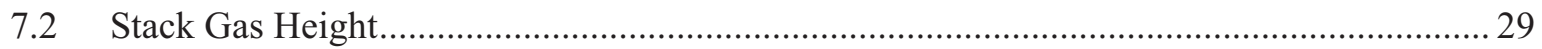

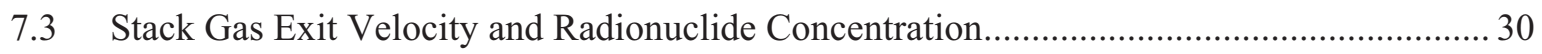

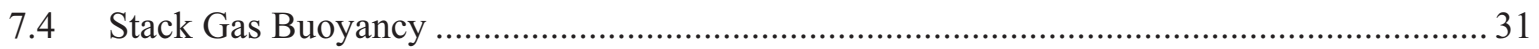

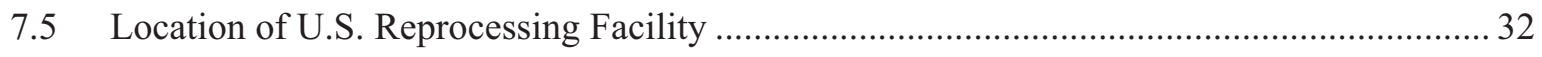




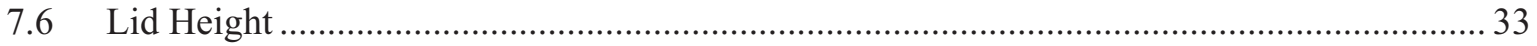

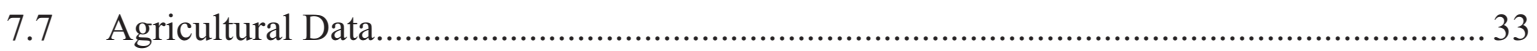

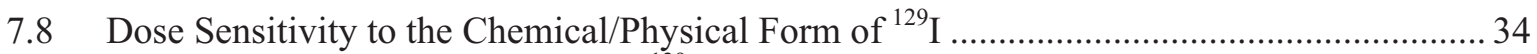

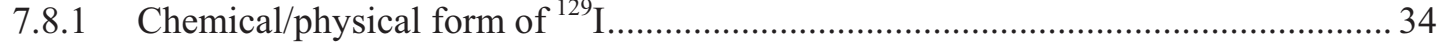

7.8.2 Sensitivity results from CAP-88 calculations ........................................................ 35

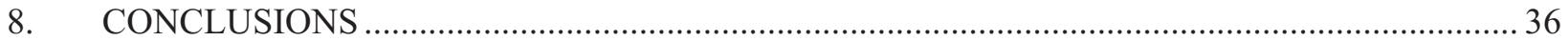

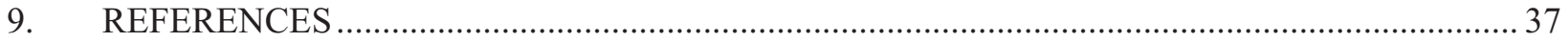




\section{FIGURES}

Figure 1. Illustration of PWR MOX assembly model (1/4 assembly shown)........................................ 10

Figure 2. Variation of ${ }^{3} \mathrm{H}$ content with cooling time (60 GWd/tIHM burn-up)..................................... 11

Figure 3. Variation of ${ }^{85} \mathrm{Kr}$ content with cooling time (60 GWd/tIHM burn-up). .................................. 11

Figure 4. Maximum plant size for processing PWR UOX fuel that would not require controls to limit exposure to the MEI to below $25 \mathrm{mrem} / \mathrm{y}$.

Figure 5. Total whole body dose and dose contributions arising from uncontrolled volatile radionuclides to the MEI from a $1000 \mathrm{t} / \mathrm{y}$ recycle plant processing $30 \mathrm{GWd} / \mathrm{tIHM} \mathrm{PWR}$ UOX fuel.

Figure 6. Total whole body dose and dose contributions arising from volatile radionuclides to the MEI from a $1000 \mathrm{t} / \mathrm{y}$ recycle plant processing $30 \mathrm{GWd} / \mathrm{tIHM}$ PWR UOX fuel with iodine and krypton controls per 40 CFR 190.

Figure 7. Total whole body dose and dose contributions arising from volatile radionuclides to the MEI from a $1000 \mathrm{t} / \mathrm{y}$ recycle plant processing $30 \mathrm{GWd}$ /tIHM PWR UOX fuel with iodine and krypton controls per 40 CFR 190.

Figure 8. Dose to MEI total and dose contribution from each of the volatile radionuclides, as a function of fuel age for a $1000 \mathrm{t} / \mathrm{y}$ recycle plant processing $30 \mathrm{GWd} / \mathrm{tIHM}$ PWR UOX fuel.

Figure 9. Dose to MEI total and dose contribution from each of the volatile radionuclides, as a function of fuel age for a $1000 \mathrm{t} / \mathrm{y}$ recycle plant processing $30 \mathrm{GWd} / \mathrm{tIHM}$ PWR UOX fuel.

Figure 10. Required DFs for each of the volatile radionuclides, as a function of fuel age for a 1000 t/y recycle plant processing $30 \mathrm{GWd} / \mathrm{tIHM}$ PWR UOX fuel.

Figure 11. Dose to the thyroid and dose contribution from each of the volatile radionuclides, as a function of fuel age for a $1000 \mathrm{t} / \mathrm{y}$ recycle plant processing $30 \mathrm{GWd} / \mathrm{tIHM}$ PWR UOX fuel.

Figure 12. Dose to the thyroid and thyroid dose contribution from each of the volatile radionuclides, as a function of fuel age for a $1000 \mathrm{t} / \mathrm{y}$ recycle plant processing 30 GWd/tIHM PWR UOX fuel.

Figure 13. Dose to the thyroid and dose contribution from each of the volatile radionuclides, as a function of fuel age for a $1000 \mathrm{t} / \mathrm{y}$ recycle plant processing $30 \mathrm{GWd} / \mathrm{tIHM}$ PWR UOX fuel. 



\section{TABLES}

Table 1. Relevant exposure/concentration values for volatile radionuclides from Appendix B to

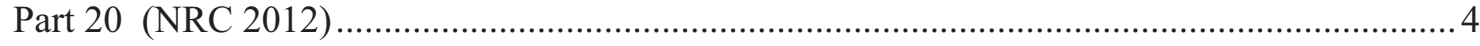

Table 2. Densities and isotope compositions for the MOX fuel used in this study …............................ 8

Table 3. Impurity content in LEU and MOX fuels ......................................................................... 9

Table 4. Source terms, by isotope, for an LWR with UOX fuel as a function of time since

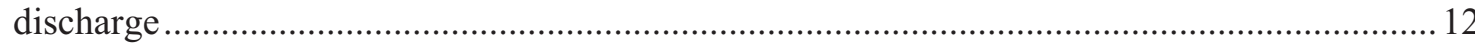

Table 5. Source terms, by isotope, for an LWR with MOX fuel as a function of time since

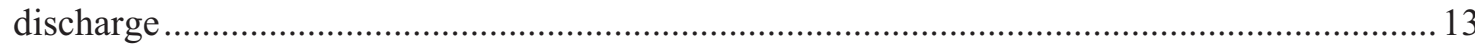

Table 6. Source terms, by isotope, for PBR reactor with UOX fuel as a function of time since discharge

Table 7. Dose contributions (mrem/y) by radionuclide based on $30 \mathrm{GWd} / \mathrm{tIHM}$ PWR UOX fuel cooled up to $200 \mathrm{y}$ and processed in a $1000 \mathrm{t} / \mathrm{y}$ recycle plant without effluent controls

Table 8. Effective DFs required to achieve $25 \mathrm{mrem} / \mathrm{y}$ whole body dose to MEI for 30 GWd/tIHM PWR UOX fuel processed in a $1000 \mathrm{t} / \mathrm{y}$ facility

Table 9. Effective DFs required to achieve $2.5 \mathrm{mrem} / \mathrm{y}$ dose to MEI for $30 \mathrm{GWd} / \mathrm{tIHM}$ PWR UOX fuel processed in a $1000 \mathrm{t} / \mathrm{y}$ facility

Table 10. Dose contributions (mrem/y) by radionuclide based on $30 \mathrm{GWD} / \mathrm{tIHM}$, PWR UOX fuel

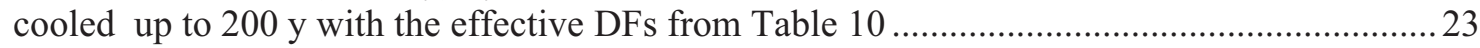

Table 11. A summary of DF requirements for the processing of PWR UOX in a $1000 \mathrm{t} / \mathrm{y}$ facility ...........26

Table 12. A summary of DF requirements for the processing of PWR UOX in a $1000 \mathrm{t} / \mathrm{y}$ facility ...........26

Table 13. A summary of DF requirements for the processing of PWR MOX in a $1000 \mathrm{t} / \mathrm{y}$ facility ..........27

Table 14. A summary of DF requirements for the processing of PWR MOX in a $1000 \mathrm{t} / \mathrm{y}$ facility ..........27

Table 15. A summary of DF requirements for the processing of AHTGR UOX in a $1000 \mathrm{t} / \mathrm{y}$

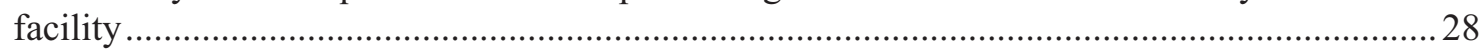

Table 16. A summary of DF requirements for the processing of AHTGR UOX in a $1000 \mathrm{t} / \mathrm{y}$

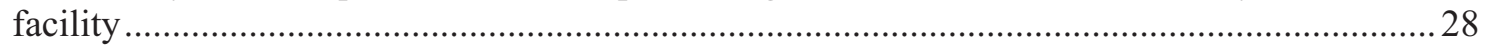

Table 17. Impact of a change in stack height from $37 \mathrm{~m}$ to $74 \mathrm{~m}$ on dose ........................................... 30

Table 18. Impact of stack gas exit velocity and radionuclide concentration on dose ...............................31

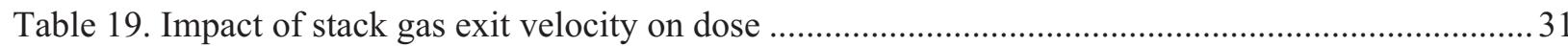

Table 20. Impact of stack gas density difference compared to the atmosphere relative to the case of $\Delta \mathrm{T}=5{ }^{\circ} \mathrm{C}$ on dose 32

Table 21. Impact of U.S. location of facility on dose relative to the base case of the northwestern United States .33

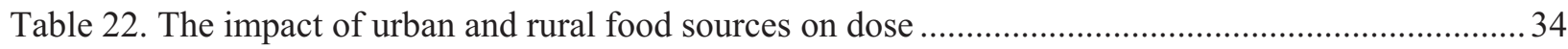

Table 23. Atmospheric iodine speciation in the vicinity of the WAK .....................................................35

Table 24. Results of the sensitivity study on the distribution of dose from $0.00482 \mathrm{mCi}$ of ${ }^{129} \mathrm{I}$ in different chemical forms to the MEI located $700 \mathrm{~m}$ from the stack of a reprocessing plant hypothetically located in the Northwest 36

Table 25. Maximum DFs required for the volatile radionuclides of concern in this report. 37 



\section{ACRONYMS}

AHTGR Advanced High Temperature Gas-Cooled Reactor

ALI annual limit on intake

CFR Code of Federal Regulations

$\mathrm{Ci} \quad$ curies

DAC derived air concentration

DF decontamination factor

DOE U.S. Department of Energy

EPA U.S. Environmental Protection Agency

GW gigawatt $\left(10^{9} \mathrm{~W}\right)$

GWd gigawatt-day

GWy gigawatt-y

IHM initial heavy metal (mass of fuel before irradiation)

LEU low-enriched uranium (enrichment with respect to ${ }^{235} \mathrm{U}$ )

MOX mixed oxide (a nuclear fuel that consists of both $\mathrm{UO}_{2}$ and $\mathrm{PuO}_{2}$ )

mrem millirem

$\mathrm{mSv} \quad$ milliseverts

MT metric ton $(1000 \mathrm{~kg})$

MW megawatt $\left(10^{6} \mathrm{~W}\right)$

MWd megawatt-day

NRC U.S. Nuclear Regulatory Commission

PBR pebble bed reactor

PWR pressurized water reactor

rem Röntgen equivalent man (mammal)

scfm standard cubic foot per minute tonne (metric ton or $1000 \mathrm{~kg}$ )

UOX uranium oxide fuel

WG weapon-grade (refers to the source of $\mathrm{Pu}$ ) 



\section{POSITION PAPER ON PRACTICABLE PERFORMANCE CRITERIA FOR THE REMOVAL EFFICIENCY OF VOLATILE RADIONUCLIDES}

\section{INTRODUCTION}

As part of the advanced fuel cycle effort, reprocessing of used nuclear fuel is being considered (DOE 2010). Since the time of previous fuel reprocessing investigations, new regulations have been put in place to govern the release of radionuclides from a reprocessing plant and the rest of the fuel cycle. Within the scope of this study, the volatile radionuclides ${ }^{3} \mathrm{H},{ }^{14} \mathrm{C},{ }^{85} \mathrm{Kr}$, and ${ }^{129} \mathrm{I}$ are, in part, the nuclides that will need to be controlled to meet these regulations. The impact of these regulations on the emissions control efficiencies needed for these radionuclides and the impact of fuel age on the required control efficiencies, expressed as decontamination factors (DFs), are the subjects of this document.

Release of radionuclides from the entire fuel cycle is regulated by 40 CFR 190 (EPA 2010b). This regulation states that

The annual dose equivalent does not exceed 25 millirems to the whole body, 75 millirems to the thyroid, and 25 millirems to any other organ of any member of the public as the result of exposures to planned discharges of radioactive materials, radon and its daughters excepted, to the general environment from uranium fuel cycle operations and to radiation from these operations...

and

The total quantity of radioactive materials entering the general environment from the entire uranium fuel cycle, per gigawatt-year of electrical energy produced by the fuel cycle, contains less than 50,000 curies of krypton-85, 5 millicuries of iodine-129, and 0.5 millicuries combined of plutonium-239 and other alpha-emitting transuranic radionuclides with half-lives greater than one year...

The latter restriction has the greatest impact on the operation of a reprocessing plant, because it regulates the release of the volatile radionuclides, with iodine and krypton being mentioned explicitly. Additionally, 10 CFR 20 (NRC 2012) and 40 CFR 61(EPA 2010a) regulate the doses to the maximally exposed individual (MEI) near a reprocessing plant, primarily from stack releases. To meet these release restrictions for a plant, certain DFs are needed for the removal of these radionuclides from the gaseous effluent.

In an aqueous reprocessing plant, volatile radionuclides come from the fuel during decladding and dissolution. In the facility these nuclides evolve from the cell ventilation, the dissolver off-gas, and the vessel off-gas systems. The amount of each of these radionuclides depends on the fuel burn-up and the storage time since its removal from the reactor. The concentration of these radionuclides in the various gas streams from which they must be removed depends on the fuel throughput and the size of the plant (gas flow rates).

Thus, the factors that play an important role in the required DFs for the volatile radionuclides are fuel age (time since irradiation), plant size (fuel throughput), and fuel burn-up. These result in the amount of volatile radionuclide per unit mass of irradiated fuel and the volume of gas from which these 
radionuclides must be removed to meet the regulations. The pertinent regulations are set forth in 40 CFR 190 (EPA 2010b), 10 CFR 20 (NRC 2012), and 40 CFR 61(EPA 2010a). However, since the half-lives of ${ }^{14} \mathrm{C}$ and ${ }^{129} \mathrm{I}$ are very long relative to the likely fuel storage times, only the relatively shortlived radionuclides ${ }^{3} \mathrm{H}$ and ${ }^{85} \mathrm{Kr}$ are affected by storage times. The total inventory of these radionuclides scales more or less linearly with fuel burn-up. In general, the larger the plant throughput, the higher are the gas flow rates and, hence, the lower are the concentrations of radionuclides. In this document, we analyze the effects of fuel type, fuel burn-up, and plant size on the required DFs for the volatile radionuclides to make the plant compliant with regulations.

\section{REVIEW OF REGULATORY REQUIREMENTS}

Volatile radionuclide emissions from a nuclear fuel recycle facility are addressed in several regulatory documents. The U.S. Environmental Protection Agency (EPA) has established through 40 CFR 190 annual dose limits resulting from nuclear fuel cycle facilities in the commercial sector (EPA 2010b). In 40 CFR 190.10, the dose limits for specific organs and for the whole body are provided. Specific release limits for ${ }^{85} \mathrm{Kr}$, ${ }^{129} \mathrm{I}$, and ${ }^{239} \mathrm{Pu}$ in terms of curies (Ci) released per unit of electric power produced are also defined in 40 CFR 190 (EPA 2010b). Dose limits for both workers and individual members of the public for facilities have been established in 10 CFR 20 and regulated by the U.S. Nuclear Regulatory Commission (NRC) (NRC 2012). Dose limits at U.S. Department of Energy (DOE) facilities for both workers and individual members have been established in 40 CFR 61.92 (EPA 2010a).

\subsection{CFR 190}

The provisions of this section are applicable to radiation doses received by members of the public in the general environment and to radioactive materials introduced into the general environment as the result of operations that are part of a nuclear fuel cycle. Section 40 CFR 190.10 provides the standards for normal operation:

(a) The annual dose equivalent does not exceed 25 millirems (mrem) to the whole body, 75 mrem to the thyroid, and 25 mrem to any other organ of any member of the public as the result of exposures to planned discharges of radioactive materials, radon and its daughters excepted, to the general environment from uranium fuel cycle operations and to radiation from these operations.

(b) The total quantity of radioactive materials entering the general environment from the entire uranium fuel cycle, per gigawatt-year of electrical energy produced by the fuel cycle, contains less than $50000 \mathrm{Ci}$ of ${ }^{85} \mathrm{Kr}, 5 \mathrm{mCi}$ of ${ }^{129} \mathrm{I}$, and 0.5 millicuries combined of 239Pu and other alphaemitting transuranic radionuclides with half-lives greater than one year.

For the purposes of this regulation, organ means any human organ exclusive of the dermis, the epidermis, or the cornea.

\subsection{CFR 20}

Sections of 10 CFR 20 that apply to this analysis of compliance to dose regulations for the gaseous fission products $\left({ }^{3} \mathrm{H},{ }^{14} \mathrm{C},{ }^{85} \mathrm{Kr}\right.$, and $\left.{ }^{129} \mathrm{I}\right)$ are excerpted below for reference in this report. 


\subsubsection{CFR 20.1001 purpose}

This regulation establishes "standards for protection against ionizing radiation resulting from activities conducted under licenses issued by the NRC. These regulations are issued under the Atomic Energy Act of 1954, as amended (AEC 1954), and the Energy Reorganization Act of 1974, as amended (USA 1974).

Section 10 CFR 20.1301 establishes the dose limits for individual members of the public and states that:

(a) Each licensee shall conduct operations so that-

(1) The total effective dose equivalent to individual members of the public from the licensed operation does not exceed $0.1 \mathrm{rem}(1 \mathrm{mSv})$ in a year, exclusive of the dose contributions from background radiation, from any medical administration the individual has received, from exposure to individuals administered radioactive material and released under $\S 35.75$, from voluntary participation in medical research programs, and from the licensee's disposal of radioactive material into sanitary sewerage in accordance with $\$ 20.2003$, and

(2) The dose in any unrestricted area from external sources, exclusive of the dose contributions from patients administered radioactive material and released in accordance with $\$ 35.75$, does not exceed $0.002 \mathrm{rem}(0.02 \mathrm{mSv})$ in any one hour.

(b) In addition to the requirements of this part, a licensee subject to the provisions of EPA's generally applicable environmental radiation standards in 40 CFR part 190 shall comply with those standards.

\subsubsection{CFR 20.1302 compliance with dose limits for individual members of the public}

a. The licensee shall make or cause to be made, as appropriate, surveys of radiation levels in unrestricted and controlled areas and radioactive materials in effluents released to unrestricted and controlled areas to demonstrate compliance with the dose limits for individual members of the public in $\$ 20.1301$.

b. A licensee shall show compliance with the annual dose limit in $\$ 20.1301$ by-

(1) Demonstrating by measurement or calculation that the total effective dose equivalent to the individual likely to receive the highest dose from the licensed operation does not exceed the annual dose limit; or

(2) Demonstrating that-

(i) The annual average concentrations of radioactive material released in gaseous and liquid effluents at the boundary of the unrestricted area do not exceed the values specified in Table 2 of appendix B to part 20; and (ii) If an individual were continuously present in an unrestricted area, the dose from external sources would not exceed 0.002 rem $(0.02 \mathrm{mSv})$ in an hour and $0.05 \mathrm{rem}(0.5 \mathrm{mSv})$ in a year. (c) Upon approval from the Commission, the licensee may adjust the effluent concentration values in appendix $B$ to part 20, table 2, for members of the public, to take into account the actual physical and chemical characteristics of the effluents (e.g., aerosol size distribution, solubility, density, radioactive decay equilibrium, chemical form).

Table 1 provides selected exposure and concentration limits for the radionuclides of interest for this study. 
Table 1. Relevant exposure/concentration values for volatile radionuclides from Appendix B to Part 20 (NRC 2012)

In this table, "Table 1" and "Table 2" refer to the tables in Part 20, Appendix B

\begin{tabular}{|c|c|c|c|c|c|c|c|c|}
\hline \multirow[b]{3}{*}{$\begin{array}{l}\text { Atomic } \\
\text { Number }\end{array}$} & \multirow[b]{3}{*}{ Radionuclide } & \multirow[b]{3}{*}{ Class } & \multicolumn{3}{|c|}{$\begin{array}{c}\text { Table } 1 \\
\text { Occupational Values }\end{array}$} & \multicolumn{2}{|c|}{$\begin{array}{c}\text { Table } 2 \\
\text { Effluent Concentration }\end{array}$} & \multirow[t]{2}{*}{\begin{tabular}{|c|} 
Table 3 \\
Releases to Sewers \\
\end{tabular}} \\
\hline & & & $\begin{array}{c}\text { Col } 1 \\
\text { Oral } \\
\text { Ingestion } \\
\end{array}$ & $\begin{array}{c}\text { Col } 2 \\
\text { Inhalation }\end{array}$ & Col 3 & Col 1 & Col 2 & \\
\hline & & & $\begin{array}{c}\text { ALI } \\
(\mu \mathrm{Ci})\end{array}$ & $\begin{array}{c}\mathrm{ALI} \\
(\mu \mathrm{Ci}) \\
\end{array}$ & $\begin{array}{c}\text { DAC } \\
(\mu \mathrm{Ci} / \mathrm{ml})\end{array}$ & $\underset{(\mu \mathrm{Ci} / \mathrm{ml})}{\operatorname{Air}}$ & $\begin{array}{c}\text { Water } \\
(\mu \mathrm{Ci} / \mathrm{ml})\end{array}$ & $\begin{array}{c}\text { Monthly Average } \\
\text { Concentration } \\
(\mu \mathrm{Ci} / \mathrm{ml})\end{array}$ \\
\hline 1 & Hydrogen-3 & $\begin{array}{l}\text { Water, DAC } \\
\text { includes skin } \\
\text { adsorption }\end{array}$ & $8 \times 10^{4}$ & $8 \times 10^{4}$ & $2 \times 10^{-5}$ & $1 \times 10^{-7}$ & $1 \times 10^{-3}$ & $1 \times 10^{-2}$ \\
\hline \multirow[t]{3}{*}{6} & Carbon-14 & Monoxide & - & $2 \times 10^{6}$ & $7 \times 10^{-4}$ & $2 \times 10^{-6}$ & - & - \\
\hline & & Dioxide & - & $2 \times 10^{5}$ & $9 \times 10^{-5}$ & $3 \times 10^{-7}$ & - & - \\
\hline & & Compounds & $2 \times 10^{3}$ & $2 \times 10^{3}$ & $1 \times 10^{-6}$ & $3 \times 10^{-9}$ & $3 \times 10^{-5}$ & $3 \times 10^{-4}$ \\
\hline \multirow[t]{2}{*}{36} & Krypton-81 & Submersion & - & - & $7 \times 10^{-4}$ & $3 \times 10^{-6}$ & - & - \\
\hline & Krypton-85 & Submersion & & & $1 \mathrm{E}-4$ & 7 E-7 & & \\
\hline 53 & Iodine-129 & $\begin{array}{l}\mathrm{D}, \text { all } \\
\text { compounds }\end{array}$ & $\begin{array}{c}5 \\
\text { Thyroid } \\
(20)\end{array}$ & $\begin{array}{c}9 \\
\text { Thyroid } \\
(30)\end{array}$ & $4 \times 10^{-9}$ & $\begin{array}{c}- \\
4 \times 10^{-11}\end{array}$ & $\begin{array}{c}- \\
2 \times 10^{-7}\end{array}$ & $\begin{array}{c}- \\
2 \times 10^{-6}\end{array}$ \\
\hline
\end{tabular}

${ }^{1}$ Gas (HT or $\mathrm{T}_{2}$ ) Submersion: Use above values as HT and $\mathrm{T}_{2}$ oxidize in air and in the body to HTO

\subsubsection{Definitions}

Annual limit on intake (ALI) means the derived limit for the amount of radioactive material taken into the body of an adult worker by inhalation or ingestion in a year. The ALI is the smaller value of intake of a given radionuclide in a year by the reference man that would result in a committed effective dose equivalent of $5 \mathrm{rem}(0.05 \mathrm{~Sv})$ or a committed dose equivalent of $50 \mathrm{rem}(0.5 \mathrm{~Sv})$ to any individual organ or tissue. (The ALI values for intake by ingestion and inhalation of selected radionuclides are given in Table 1, Columns 1 and 2, of Appendix B to $\S \S 20.1001-20.2401$ ).

Derived air concentration (DAC) means the concentration of a given radionuclide in air, which, if breathed by the reference man for a working year of 2000 hours under conditions of light work (inhalation rate 1.2 cubic meters of air per hour), results in an intake of one ALI. The DAC values are given in Table 1, Column 3, of Appendix B to $\S \S 20.1001-20.2401$.

\subsubsection{How compliance to 10 CFR 20 is addressed in this report}

Table 2 of 10 CFR 20 Appendix B (NRC 2012) defines limits for annual average concentrations of radioactive material released in gaseous and liquid effluents at the boundary of an unrestricted area (the "fence line" that would surround a used fuel reprocessing facility). These limits are based on an annual dose limit to an individual member of the public in the unrestricted area (just outside the fence line) of 0.05 rem (10 CFR 20.1302) (NRC 2012).

\subsubsection{Mixture rule}

A stack gas from a reprocessing facility could contain any isotopes (or progeny of isotopes) in the used fuel that is being processed. Off-gas control processes, such as scrubbing and filtration, would be 
designed to capture most isotopes with efficiencies high enough to comply with all emissions regulations including 10 CFR 20. The focus of this report is the determination of the levels of control needed for the gaseous fission products ${ }^{3} \mathrm{H},{ }^{14} \mathrm{C},{ }^{85} \mathrm{Kr}$, and ${ }^{129} \mathrm{I}$.

The determination of capture efficiencies needed for the gaseous fission products is complicated by the potential for other radionuclides (some of which have very low derived air concentrations [DACs]) to be present in the reprocessing facility off-gas. If the identity and concentration of each radionuclide in a mixture is known, the limiting value for each radionuclide is derived by the "sum of the fractions" rule. Following this rule, the maximum concentration of any radionuclide in the mixture is determined by dividing the concentration of the radionuclide by its single-component DAC from Table 2 of Appendix B (NRC 2012), and then summing those fractions for all radionuclides in the mixture. The sum of these ratios for all of the radionuclides in the mixture may not exceed "1" (i.e., unity).

Example: If radionuclides $\mathrm{A}, \mathrm{B}$, and $\mathrm{C}$ are present in concentrations $\mathrm{C}_{\mathrm{A}}, \mathrm{C}_{\mathrm{B}}$, and $\mathrm{C}_{\mathrm{C}}$ and if the applicable DACs are $\mathrm{DAC}_{\mathrm{A}}, \mathrm{DAC}_{\mathrm{B}}$, and $\mathrm{DAC}_{\mathrm{C}}$, respectively, then the concentration shall be limited so that the following relationship exists:

$$
\frac{C_{A}}{D A C_{A}}+\frac{C_{B}}{D A C_{B}}+\frac{C_{C}}{D A C_{C}} \leq 1
$$

\subsubsection{When all radionuclides in a mixture are unknown}

However, if the identity of each radionuclide in a mixture is known, but the concentration of one or more of the radionuclides in the mixture is unknown, the DAC for the mixture shall be the most restrictive DAC of any radionuclide in the mixture. Or if the identity of each radionuclide in the mixture is unknown, but certain radionuclides specified in this appendix are not present in the mixture, the inhalation ALI and $D A C$ for the mixture are the lowest values specified in Appendix $B$ for any radionuclide that is not known to be absent from the mixture. If it cannot be shown that isotopes such as ${ }^{227} \mathrm{Ac},{ }^{229} \mathrm{Th},{ }^{232} \mathrm{Th},{ }^{231} \mathrm{~Pa},{ }^{248} \mathrm{Cm}$,

or ${ }^{250} \mathrm{Cm}$ are not present, then the most restrictive DAC would be $1 \times 10^{-15} \mu \mathrm{Ci} / \mathrm{mL}$. Comparing this to the DACs for the isotopes of interest, it is apparent that this would impose a requirement to reduce the dose from these isotopes by an additional factor of $10^{4}$ to $\sim 10^{9}$, which would significantly increase the challenge of capturing these volatile radionuclides.

For this study, we know that the stack effluent will contain a number of additional radionuclides. This will be primarily particulates. The bulk of these will be removed by the HEPA filters and other scrubber on the off-gas systems, but any (expectedly very small) amounts of these other radionuclides in the stack gas must be accounted for in the total exposure to the maximum exposed individual (MEI). Accounting for the identity and concentration of every radionuclide in the effluent from the stack, besides the gaseous fission products, is outside the scope of this study. Also, for this study, it is overly restrictive to impose the most restrictive DAC to the four radionuclides of interest, because in an actual design for a real reprocessing facility, the identities and concentrations of those other radionuclides would be accounted for.

The scope of this study is restricted to just the four gaseous fission products by restricting the potential dose from the gaseous fission products to a level that could cause an "insignificant" impact on how a reprocessing facility might comply with 10 CFR 20, considering the total dose from all the radionuclides that might be present in the stack gas. In this way, the dose from any single gaseous fission product, or the total dose from all the gaseous fission products, would not, by itself, cause the facility's air emissions to be out of compliance. The largest reasonable "insignificant" amount might be $10 \%$ of the total. This 
approach allocates, to all other radionuclides that might be in the stack gas, $90 \%$ of the effective dose limit to the MEI.

With this approach, the dose to the public in 20.1302 is reduced from the total of $50 \mathrm{mrem} / \mathrm{y}$ to $5 \mathrm{mrem} / \mathrm{y}$ for the four gaseous fission products. As a result we will establish an effective DAC for the four radionuclides of interest by reducing the DACs in Table 2, Appendix B, by a factor of 10 . This approach reserves a majority of the allowable dose for other radionuclides. Some of these other radionuclides, such as ${ }^{227} \mathrm{Ac},{ }^{229} \mathrm{Th},{ }^{232} \mathrm{Th},{ }^{231} \mathrm{~Pa},{ }^{248} \mathrm{Cm}$, and ${ }^{250} \mathrm{Cm}$, have very low DACs, ranging as low as $1 \times 10^{-15} \mu \mathrm{Ci} / \mathrm{mL}$. These low DACs are more easily met for these solid and particulate-phase (nongaseous) radionuclides because they typically have different process release factors, control technologies, and control efficiencies. Methods for estimating radionuclide emissions are provided in 40 CFR 61 Appendix D (EPA 2010a). Radionuclide emission factors have also been reported elsewhere (Abbott 1999 and Soelberg et al. 2008). These references have indicated a total DF ranging from 1 to 10 for gaseous fission products (with traditional scrubbing and filtration technologies), and much higher DFs, ranging from $10^{7}$ to $10^{11}$, for these other radionuclides known to persist in liquid, particulate, and solid forms. Trying to achieve such high DFs for gaseous fission products would be impractical at best and unneeded to meet the emissions regulations in 10 CFR 20, 40 CFR 61, and 40 CFR 190.

\section{$2.3 \quad 40$ CFR 61}

This part applies to operations at any facility owned or operated by DOE from which any radionuclide other than ${ }^{222} \mathrm{Rn}$ and ${ }^{220} \mathrm{Rn}$ is emitted into the air, except that this part does not apply to disposal at facilities subject to 40 CFR part 191 subpart B or 40 CFR part 192 (EPA 2010a).

This regulation establishes that the

emissions of radionuclides to the ambient air from Department of Energy facilities shall not exceed those amounts that would cause any member of the public to receive in any year an effective dose equivalent of $10 \mathrm{mrem} / \mathrm{y}$.

It is also noted that

demonstration of compliance will be based on 10 CFR 20 methodology by reduction of DAC by appropriate factor of 5 (see notes on development of Table 2 (Appendix $B$ to Part 20).

So to summarize:

Under 40 CFR 190 (EPA 2010b), the total quantity of iodine and krypton that may be released to the environment from the entire fuel cycle is limited to $5 \mathrm{mCi}$ of ${ }^{129} \mathrm{I}$ and $50,000 \mathrm{mCi}$ of ${ }^{85} \mathrm{Kr}$ per gigawattyear (GWy) of electrical energy produced by the fuel cycle. The most restrictive dose limit ( $10 \mathrm{mrem} / \mathrm{y}$ to the public) is established by 40 CFR 61 (EPA 2010a). In 10 CFR 20 (NRC 2012), the limit is set at 100 $\mathrm{mrem} / \mathrm{y}$, but a demonstration of compliance level of $50 \mathrm{mrem} / \mathrm{y}$ value is added. Two key values are set in 40 CFR 190 - a limit to the whole body of $25 \mathrm{mrem} / \mathrm{y}$ and to the thyroid of $75 \mathrm{mrem} / \mathrm{y}$. Since the values specified in 40 CFR 190 are more restrictive than those set by NRC (10 CFR 20) and the most restrictive values of $10 \mathrm{mrem} / \mathrm{y}$ apply only to DOE facilities, we will use the $25 \mathrm{mrem} / \mathrm{y}$ as the upper limit in this study. Further, an allocation factor of 0.1 will be applied to the four volatile radionuclides, resulting in a $2.5 \mathrm{mrem} / \mathrm{y}$ dose contribution from these radionuclides. While the use of only $10 \%$ of the allowable dose for these four radionuclides is arbitrary, it is just as unlikely that the full allowable dose can be assigned to 
these four radionuclides, especially in light of the very low DACs for some of the other radionuclides that are likely to be in the stack emissions from a reprocessing facility. Therefore, two cases are shown in this study. In the first, the entire allowable dose $(25 \mathrm{mrem} / \mathrm{y}$ whole body; $75 \mathrm{mrem} / \mathrm{y}$ thyroid) is assigned to these four radionuclides. In the second, only $10 \%$ of the allowable dose $(2.5 \mathrm{mrem} / \mathrm{y}$ whole body; 7.5 $\mathrm{mrem} / \mathrm{y}$ thyroid) is assigned to these four radionuclides.

\section{ASSUMPTIONS USED IN THIS STUDY}

The following assumptions and working hypotheses were used in this study.

1. Recycle facility will be licensed by NRC.

a. 40 CFR 61 is not applicable.

b. 40 CFR 190 and 10 CFR 20 applies.

2. Dose limits will be derived from 40 CFR 190 based on lower limit.

3. Allowable contribution by the four volatile radionuclides to total dose to MEI will be $10 \%$ of the total allowable dose.

4. The same factor will apply to thyroid dose.

5. No engineering margins will be applied.

6. Plant size is $1000 \mathrm{t} / \mathrm{y}$.

7. The site boundary will be at maximum plume concentrations as determined by CAP88.

8. Fuel ages are 2, 5, 10, 20, 30, 50, 70, and 100 years of cooling.

9. Fuel types are LWR (UOX), MOX, and AHGCR.

10. Burn-ups are 20,30, 60, and $100 \mathrm{GWd} / \mathrm{tIHM}$.

11. The potential for release of ${ }^{85} \mathrm{Kr}$ or ${ }^{129} \mathrm{I}$ in other parts of the fuel cycle is not considered in this study. If discrete amounts of these radionuclides are released to the atmosphere in other parts of a fuel cycle (such as during reactor operations or during used fuel storage prior to reprocessing), then the control efficiencies estimated in this study for compliance to the fuel cycle limits in 40 CFR 190 would need to be proportionately higher.

\section{SOURCE TERM CALCULATIONS}

Radionuclide inventories representative of different spent nuclear fuel types have been calculated to provide source terms for use in accident analyses and environmental impact studies. Three types of reactor/fuel configurations have been considered in this report: (1) pressurized water reactor (PWR) with low-enriched uranium (LEU) fuel; (2) PWR with mixed oxide (MOX) fuel; and (3) pebble bed reactor (PBR) with LEU fuel. Depletion simulations have been performed with the SCALE nuclear analysis code system (ORNL 2009) for configurations representative of the three considered reactors/fuels. The depletion models and the analysis methodology are summarized in this section. 


\subsection{Fuel/Reactor Data}

A Westinghouse $17 \times 17$ fuel pin assembly has been used as representative of a PWR with $\mathrm{UO}_{2} \mathrm{LEU}_{\text {fuel }}$. The assembly data were calculated with SCALE (ORNL 2009). The LEU fuel used for this report had an enrichment of 4.0 mass $\%{ }^{235} \mathrm{U}$. The impurity content used in the fresh $\mathrm{UO}_{2}$ fuel was based on data taken from ASTM C776-06 (2011). This standard specifies maximum concentration limits for $\mathrm{Al}, \mathrm{C}, \mathrm{Ca}, \mathrm{Mg}$, $\mathrm{Cl}, \mathrm{Cr}, \mathrm{Co}, \mathrm{F}, \mathrm{H}, \mathrm{Fe}, \mathrm{Ni}, \mathrm{N}, \mathrm{Si}$, and Th. The values used for impurities contents in the PWR LEU assembly model were taken as half of the maximum concentrations for this fuel (ASTM 2011).

A PWR $17 \times 17$ fuel assembly has been used as representative of a PWR with MOX fuel. Fuel and assembly design specifications used for the PWR MOX assembly model are based on data in a publicly available document prepared by FRAMATOME ANP for the DOE Office of Material Disposition (FRAMATOM 2001). In this MOX fuel, weapon-grade (WG) plutonium is used. The composition of this fuel is shown in Table 2. The $\mathrm{UO}_{2}$ and $\mathrm{PuO}_{2}$ mass fractions in Table 2 correspond to assembly-average values. The model actually included three types of fuel pins with different $\mathrm{PuO}_{2}$ mass fractions. The impurity content used in the MOX fuel was based on data taken from ASTM C833-01 (ASTM 2008). This standard specifies maximum concentration limits for $\mathrm{Al}, \mathrm{C}, \mathrm{Ca}, \mathrm{Mg}, \mathrm{Cl}, \mathrm{Cr}, \mathrm{Co}, \mathrm{F}, \mathrm{H}$, $\mathrm{Fe}, \mathrm{Ni}, \mathrm{N}, \mathrm{Si}$, and Th. The values used for impurities contents in the PWR MOX assembly model were taken as half of the provided (FRAMATOM 2001) maximum concentrations.

The PBR fuel configuration used in the present study is representative of the PBR design considered under the Next Generation Nuclear Plant (NGNP) program (MacDonald et al. 2003). The fuel material present in the TRISO kernels is $\mathrm{UC}_{0.5} \mathrm{O}_{1.5}$ at $10.5 \times 10^{3} \mathrm{~kg} / \mathrm{m}^{3}$ density and has an enrichment of 7.0 mass $\%$ ${ }^{235} \mathrm{U}$. A simplified model representative of the PBR NGNP fuel was used (Ilas and Gauld 2011), which consists of a fuel pebble surrounded by a helium coolant region. The fuel material was assumed to have the same impurities contents as used for the $\mathrm{UO}_{2}$ fuel (ASTM 2011). The impurities values used in the depletion models are listed in Table 3.

Table 2. Densities and isotope compositions for the MOX fuel used in this study

\begin{tabular}{|l|c|}
\hline \multicolumn{1}{|c|}{ Parameter } & Value, \% \\
\hline $\mathrm{UO}_{2}$ fraction & 95.63 \\
\hline $\mathrm{PuO}_{2}$ fraction & 4.37 \\
\hline $\mathrm{U} \mathrm{isotopes}^{235} \mathrm{U}$ & \\
${ }^{238} \mathrm{U}$ & 0.25 \\
\hline${ }^{\mathrm{Pu} \text { isotopic composition }}$ & 99.75 \\
${ }^{238} \mathrm{Pu}$ & \\
${ }^{239} \mathrm{Pu}$ & 0.0 \\
${ }^{240} \mathrm{Pu}$ & 93.6 \\
${ }^{241} \mathrm{Pu}$ & 5.9 \\
${ }^{242} \mathrm{Pu}$ & 0.4 \\
\hline
\end{tabular}


Table 3. Impurity content in LEU and MOX fuels

\begin{tabular}{|c|c|c|}
\hline \multirow{2}{*}{ Element } & \multicolumn{2}{|c|}{ Impurity Content in Fuel $(\boldsymbol{\mu g} / \mathbf{g})$} \\
\cline { 2 - 3 } & LEU & MOX \\
\hline $\mathrm{Al}$ & 125 & 125 \\
\hline $\mathrm{C}$ & 50 & 50 \\
\hline $\mathrm{Ca}$ & 50 & 50 \\
\hline $\mathrm{Cl}$ & 12.5 & 12.5 \\
\hline $\mathrm{Cr}$ & 125 & 125 \\
\hline $\mathrm{Co}$ & 50 & 50 \\
\hline $\mathrm{F}$ & 7.5 & 12.5 \\
\hline $\mathrm{Fe}$ & 250 & 250 \\
\hline $\mathrm{H}$ & 0.65 & 0.65 \\
\hline $\mathrm{Mg}$ & 50 & 50 \\
\hline $\mathrm{N}$ & 37.5 & 37.5 \\
\hline $\mathrm{Ni}$ & 125 & 125 \\
\hline $\mathrm{Si}$ & 250 & 125 \\
\hline $\mathrm{Th}$ & 5 & - \\
\hline
\end{tabular}

\subsection{Analysis Methodology}

The fuel depletion methodology used in this study includes two main steps. In the first step, computational models are developed for each of the three considered configurations for use with the SCALE/TRITON (DeHart and Bowman 2011) depletion sequence. Two-dimensional (2-D) geometry models are used for the PWR LEU and MOX assemblies, and a one-dimensional geometry model is used for the PBR model. The 2-D model for the PWR MOX assembly is illustrated in Figure 1. The use of different colors for fuel pin materials in Figure 1 serves to indicate different plutonium contents in the MOX fuel. The TRITON depletion models are used to simulate the fuel depletion to reach a total burn-up of $105 \mathrm{GWd}$ /tIHM. Burn-up-dependent cross-section libraries for use in standalone SCALE/ORIGEN (Gauld et al. 2011) simulations are produced with TRITON.

In the second step, the cross-section libraries generated with TRITON are used in depletion and decay simulations with the ORIGEN code. The fuel can be burned to a desired burn-up and the activity allowed to decay for desired cooling times with ORIGEN. 


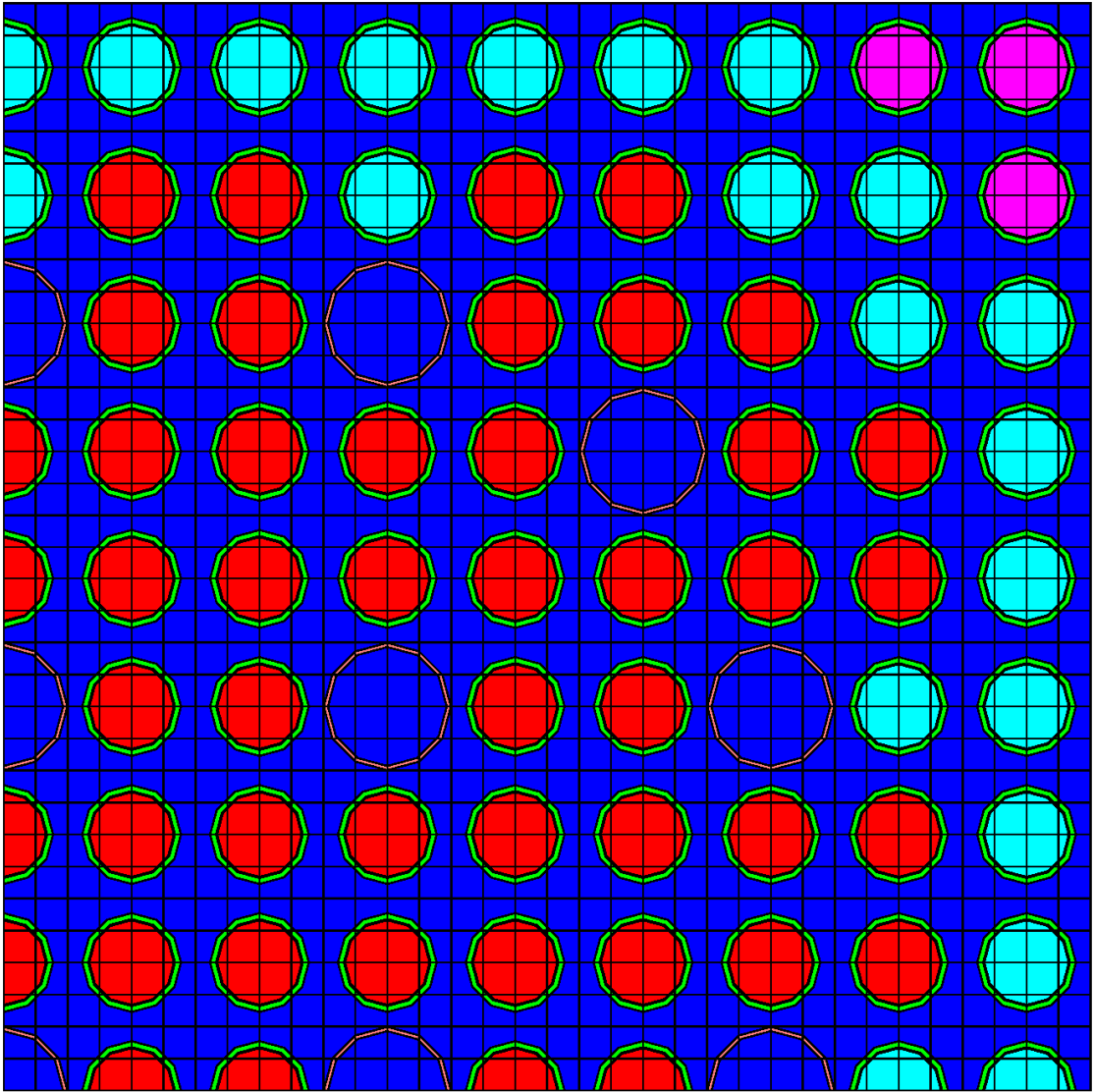

Figure 1. Illustration of PWR MOX assembly model (1/4 assembly shown).

\subsection{Results}

In the present study, ORIGEN-ARP simulations were carried out for each of the three considered fuels for total cumulative burn-up values of 20,30,60, and $100 \mathrm{GWd}$ /tIHM. For each of these burn-up cases, radionuclide inventories and activities were generated for eight cooling times: 0 (discharge), 2, 5, 10, 30, 50,70 , and $100 \mathrm{y}$.

The variation of the isotopic content of ${ }^{3} \mathrm{H}$ and ${ }^{85} \mathrm{Kr}$, nuclides of importance to environmental impact studies, is illustrated in Figures 2 and 3 as a function of cooling time for PWR LEU and PWR MOX fuels at $60 \mathrm{GWd} / \mathrm{tIHM}$ burn-up.

The quantity of ${ }^{129} \mathrm{I}$ in MOX is significantly higher than for PWR/UOX because of the higher ${ }^{129}$ I fission yield for ${ }^{239} \mathrm{Pu}$ fission (which is in large quantity in WG MOX), compared to the ${ }^{129} \mathrm{I}$ fission yield from ${ }^{235} \mathrm{U}$ fission.

In the AHTGR (PBR), there is a significant increase in the quantity of ${ }^{14} \mathrm{C}$. The fuel was considered to be the fuel pebble, which is made of two main regions: a pebble core with TRISO particles $\left(\mathrm{UC}_{0.5} \mathrm{O}_{1.5}\right.$ kernels covered by graphite-based coatings) embedded in a graphite matrix and a pebble graphite shell. The pebble core radius is $25 \mathrm{~mm}$ and the pebble outer radius is $30 \mathrm{~mm}$; hence, a significant amount of graphite is contained in the shell. In addition, the fuel itself in the fuel kernels is $\mathrm{UC}_{0.5} \mathrm{O}_{1.5}$. Note also that the volume of the $\mathrm{UC}_{0.5} \mathrm{O}_{1.5}$ fuel kernels is $\sim 1 \%$ of the pebble core volume. While the major production routes for ${ }^{14} \mathrm{C}$ are ${ }^{14} \mathrm{~N}$ (n,p) and ${ }^{17} \mathrm{O}$ (n,alpha), contribution from neutron capture in ${ }^{13} \mathrm{C}$ becomes significant when 
these quantities of graphite are present. However, if the reprocessing process does not gasify the carbon in the coatings and pebble graphite matrix, then the ${ }^{14} \mathrm{C}$ in the coatings and graphite might not be released to the off-gas systems, and the levels of ${ }^{14} \mathrm{C}$ that would require off-gas control would be lower than indicated in this report for the AHTGR fuel.

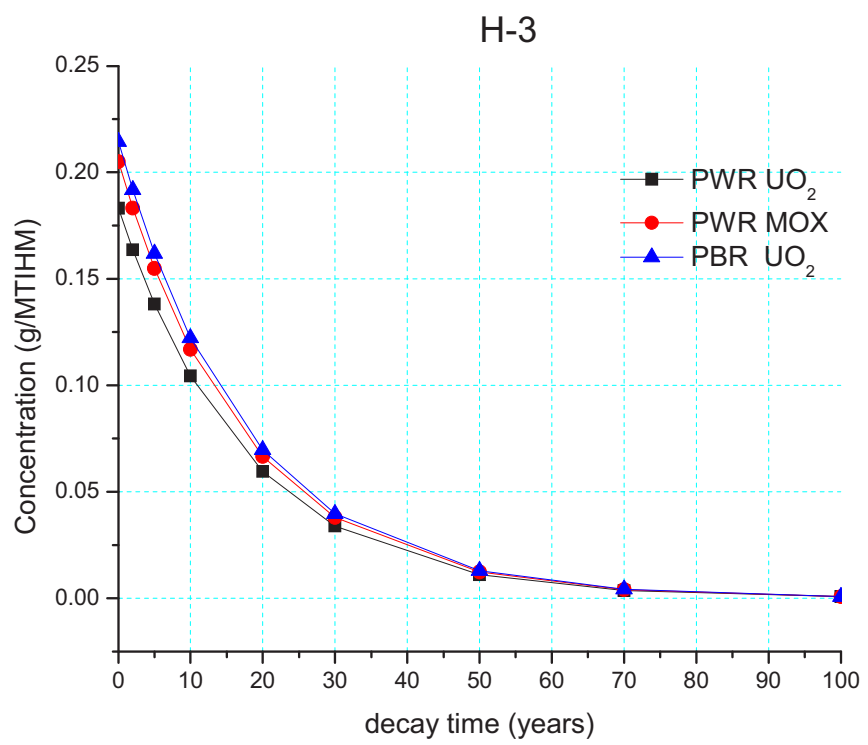

Figure 2. Variation of ${ }^{3} \mathrm{H}$ content with cooling time ( $60 \mathrm{GWd} / \mathrm{tIHM}$ burn-up).

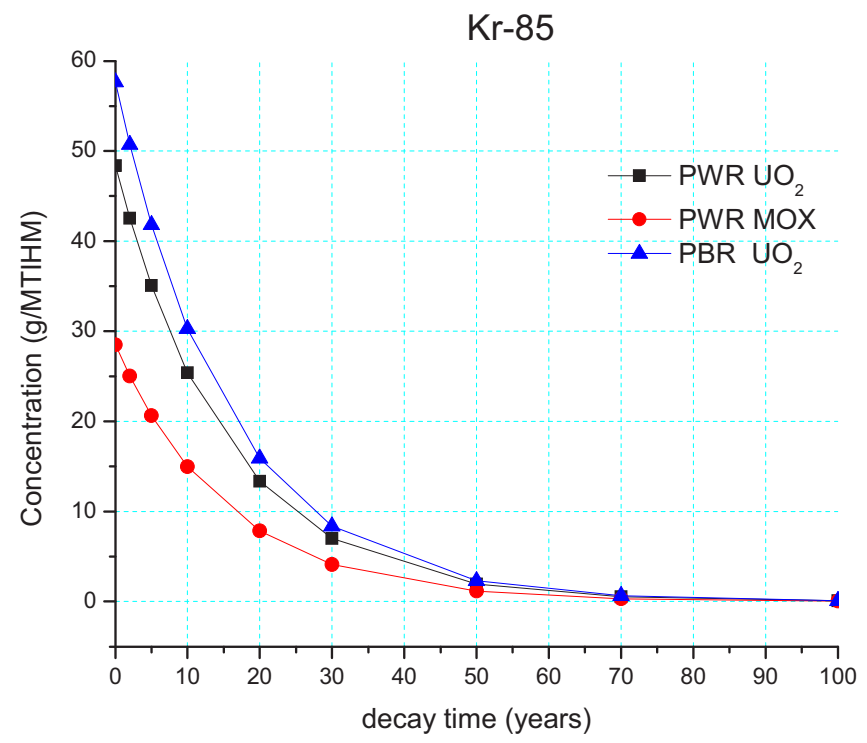

Figure 3. Variation of ${ }^{85} \mathrm{Kr}$ content with cooling time (60 GWd/tIHM burn-up).

Tables 4 to 6 provide the quantity of each of the four radionuclides of interest for each of the reactor types as a function of fuel age and burn-up. For purposes of this report, the shortest fuel cooling time considered is $2 \mathrm{y}$. At much shorter cooling times, dose contributions from Xe must also be considered. Also note that increased amount of ${ }^{129} \mathrm{I}$ in year 2 and beyond is due to the decay of ${ }^{129} \mathrm{Te}$. 
Table 4. Source terms, by isotope, for an LWR with UOX fuel as a function of time since discharge Isotopic mass (g/tIHM) - 20 GWD/MT burn-up

\begin{tabular}{|c|c|c|c|c|c|c|c|c|c|}
\hline & \multicolumn{10}{|c|}{ Time Since Discharge (y) } \\
\hline & $\mathbf{0}$ & $\mathbf{2}$ & $\mathbf{5}$ & $\mathbf{1 0}$ & $\mathbf{2 0}$ & $\mathbf{3 0}$ & $\mathbf{5 0}$ & $\mathbf{7 0}$ & $\mathbf{1 0 0}$ \\
\hline${ }^{3} \mathrm{H}$ & 0.052 & 0.047 & 0.040 & 0.030 & 0.017 & 0.010 & 0.003 & 0.001 & 0.000 \\
\hline${ }^{14} \mathrm{C}$ & 0.105 & 0.105 & 0.105 & 0.105 & 0.105 & 0.105 & 0.104 & 0.104 & 0.104 \\
\hline${ }^{85} \mathrm{Kr}$ & 22.41 & 19.71 & 16.24 & 11.77 & 6.18 & 3.24 & 0.894 & 0.246 & 0.036 \\
\hline${ }^{129} \mathrm{I}$ & 84.97 & 85.04 & 85.04 & 85.04 & 85.04 & 85.04 & 85.04 & 85.04 & 85.04 \\
\hline
\end{tabular}

Isotopic mass (g/tIHM) - 30 GWD/MT burn-up

\begin{tabular}{|c|c|c|c|c|c|c|c|c|c|}
\hline & \multicolumn{10}{|c|}{ Time Since Discharge (y) } \\
\hline & $\mathbf{0}$ & $\mathbf{2}$ & $\mathbf{5}$ & $\mathbf{1 0}$ & $\mathbf{2 0}$ & $\mathbf{3 0}$ & $\mathbf{5 0}$ & $\mathbf{7 0}$ & $\mathbf{1 0 0}$ \\
\hline${ }^{3} \mathrm{H}$ & 0.084 & 0.075 & 0.063 & 0.048 & 0.027 & 0.015 & 0.005 & 0.002 & 0.0003 \\
\hline${ }^{14} \mathrm{C}$ & 0.163 & 0.163 & 0.163 & 0.163 & 0.163 & 0.163 & 0.162 & 0.162 & 0.161 \\
\hline${ }^{85} \mathrm{Kr}$ & 30.79 & 27.08 & 22.32 & 16.17 & 8.49 & 4.46 & 1.23 & 0.338 & 0.049 \\
\hline${ }^{129} \mathrm{I}$ & 134.3 & 134.4 & 134.4 & 134.4 & 134.4 & 134.4 & 134.4 & 134.4 & 134.4 \\
\hline
\end{tabular}

Isotopic mass (g/ tIHM) - 60 GWD/MT burn-up

\begin{tabular}{|c|c|c|c|c|c|c|c|c|c|}
\hline & \multicolumn{10}{|c|}{ Time Since Discharge (y) } \\
\hline & $\mathbf{0}$ & $\mathbf{2}$ & $\mathbf{5}$ & $\mathbf{1 0}$ & $\mathbf{2 0}$ & $\mathbf{3 0}$ & $\mathbf{5 0}$ & $\mathbf{7 0}$ & $\mathbf{1 0 0}$ \\
\hline${ }^{3} \mathrm{H}$ & 0.184 & 0.164 & 0.139 & 0.105 & 0.060 & 0.034 & 0.011 & 0.0036 & 0.0007 \\
\hline${ }^{14} \mathrm{C}$ & 0.376 & 0.376 & 0.376 & 0.376 & 0.375 & 0.375 & 0.374 & 0.373 & 0.372 \\
\hline${ }^{85} \mathrm{Kr}$ & 48.45 & 42.59 & 35.11 & 25.43 & 13.35 & 7.008 & 1.931 & 0.532 & 0.077 \\
\hline${ }^{129} \mathrm{I}$ & 291.0 & 291.1 & 291.1 & 291.1 & 291.1 & 291.1 & 291.1 & 291.1 & 291.1 \\
\hline
\end{tabular}


Table 5. Source terms, by isotope, for an LWR with MOX fuel as a function of time since discharge

Isotopic mass (g/tIHM) - 20 GWD/MT burn-up

\begin{tabular}{|c|c|c|c|c|c|c|c|c|c|}
\hline & \multicolumn{10}{|c|}{ Time Since Discharge (y) } \\
\hline & $\mathbf{0}$ & $\mathbf{2}$ & $\mathbf{5}$ & $\mathbf{1 0}$ & $\mathbf{2 0}$ & $\mathbf{3 0}$ & $\mathbf{5 0}$ & $\mathbf{7 0}$ & $\mathbf{1 0 0}$ \\
\hline${ }^{3} \mathrm{H}$ & 0.059 & 0.053 & 0.045 & 0.034 & 0.019 & 0.011 & 0.004 & 0.001 & 0.000 \\
\hline${ }^{14} \mathrm{C}$ & 0.074 & 0.074 & 0.074 & 0.074 & 0.074 & 0.074 & 0.074 & 0.074 & 0.073 \\
\hline${ }^{85} \mathrm{Kr}$ & 10.89 & 9.58 & 7.90 & 5.72 & 3.00 & 1.58 & 0.43 & 0.12 & 0.02 \\
\hline${ }^{129} \mathrm{I}$ & 143.0 & 143.1 & 143.1 & 143.1 & 143.1 & 143.1 & 143.1 & 143.1 & 143.1 \\
\hline
\end{tabular}

Isotopic mass (g/tIHM) - $30 \mathrm{GWD} / \mathrm{MT}$ burn-up

\begin{tabular}{|c|c|c|c|c|c|c|c|c|c|}
\hline & \multicolumn{10}{|c|}{ Time Since Discharge (y) } \\
\hline & $\mathbf{0}$ & $\mathbf{2}$ & $\mathbf{5}$ & $\mathbf{1 0}$ & $\mathbf{2 0}$ & $\mathbf{3 0}$ & $\mathbf{5 0}$ & $\mathbf{7 0}$ & $\mathbf{1 0 0}$ \\
\hline${ }^{3} \mathrm{H}$ & 0.096 & 0.085 & 0.072 & 0.054 & 0.031 & 0.018 & 0.006 & 0.0019 & 0.0003 \\
\hline${ }^{14} \mathrm{C}$ & 0.117 & 0.117 & 0.117 & 0.117 & 0.117 & 0.117 & 0.117 & 0.116 & 0.116 \\
\hline${ }^{85} \mathrm{Kr}$ & 15.79 & 13.88 & 11.44 & 8.289 & 4.351 & 2.284 & 0.629 & 0.173 & 0.025 \\
\hline${ }^{129} \mathrm{I}$ & 209.8 & 209.9 & 209.9 & 209.9 & 209.9 & 209.9 & 209.9 & 209.9 & 209.9 \\
\hline
\end{tabular}

Isotopic mass (g/tIHM) - 60 GWD/MT burn-up

\begin{tabular}{|c|c|c|c|c|c|c|c|c|c|}
\hline & \multicolumn{10}{|c|}{ Time Since Discharge (y) } \\
\hline & $\mathbf{0}$ & $\mathbf{2}$ & $\mathbf{5}$ & $\mathbf{1 0}$ & $\mathbf{2 0}$ & $\mathbf{3 0}$ & $\mathbf{5 0}$ & $\mathbf{7 0}$ & $\mathbf{1 0 0}$ \\
\hline${ }^{3} \mathrm{H}$ & 0.205 & 0.183 & 0.155 & 0.117 & 0.067 & 0.038 & 0.012 & 0.0040 & 0.0007 \\
\hline${ }^{14} \mathrm{C}$ & 0.272 & 0.272 & 0.271 & 0.271 & 0.271 & 0.271 & 0.270 & 0.269 & 0.268 \\
\hline${ }^{85} \mathrm{Kr}$ & 28.49 & 25.04 & 20.64 & 14.96 & 7.851 & 4.121 & 1.136 & 0.313 & 0.045 \\
\hline${ }^{129} \mathrm{I}$ & 391.8 & 391.9 & 391.9 & 391.9 & 391.9 & 391.9 & 391.9 & 391.9 & 391.9 \\
\hline
\end{tabular}

Isotopic mass (g/tIHM) - $100 \mathrm{GWD} / \mathrm{MT}$ burn-up

\begin{tabular}{|c|c|c|c|c|c|c|c|c|c|}
\hline & \multicolumn{10}{|c|}{ Time Since Discharge (y) } \\
\hline & $\mathbf{0}$ & $\mathbf{2}$ & $\mathbf{5}$ & $\mathbf{1 0}$ & $\mathbf{2 0}$ & $\mathbf{3 0}$ & $\mathbf{5 0}$ & $\mathbf{7 0}$ & $\mathbf{1 0 0}$ \\
\hline${ }^{3} \mathrm{H}$ & 0.347 & 0.311 & 0.262 & 0.198 & 0.113 & 0.064 & 0.021 & 0.0068 & 0.0013 \\
\hline${ }^{14} \mathrm{C}$ & 0.536 & 0.536 & 0.536 & 0.536 & 0.535 & 0.534 & 0.533 & 0.532 & 0.530 \\
\hline${ }^{85} \mathrm{Kr}$ & 42.07 & 36.99 & 30.48 & 22.09 & 11.59 & 6.086 & 1.677 & 0.462 & 0.067 \\
\hline${ }^{129} \mathrm{I}$ & 602.7 & 602.8 & 602.8 & 602.8 & 602.8 & 602.8 & 602.8 & 602.8 & 602.8 \\
\hline
\end{tabular}


Table 6. Source terms, by isotope, for PBR reactor with UOX fuel as a function of time since discharge

Isotopic mass (g/tIHM) - 20 GWd/t burn-up

\begin{tabular}{|c|c|c|c|c|c|c|c|r|r|}
\hline \multirow{2}{*}{ Isotope } & \multicolumn{8}{|c|}{ Time Since Discharge (y) } \\
\cline { 2 - 11 } & $\mathbf{0}$ & $\mathbf{2}$ & $\mathbf{5}$ & $\mathbf{1 0}$ & $\mathbf{2 0}$ & $\mathbf{3 0}$ & $\mathbf{5 0}$ & $\mathbf{7 0}$ & $\mathbf{1 0 0}$ \\
\hline${ }^{3} \mathrm{H}$ & 0.086 & 0.077 & 0.065 & 0.049 & 0.028 & 0.016 & 0.0052 & 0.0017 & 0.0003 \\
\hline${ }^{14} \mathrm{C}$ & 0.278 & 0.278 & 0.277 & 0.277 & 0.277 & 0.277 & 0.276 & 0.275 & 0.274 \\
\hline${ }^{85} \mathrm{Kr}$ & 23.94 & 21.07 & 17.36 & 12.58 & 6.603 & 3.466 & 0.955 & 0.263 & 0.038 \\
\hline${ }^{129} \mathrm{I}$ & 80.64 & 80.77 & 80.77 & 80.77 & 80.77 & 80.77 & 80.77 & 80.77 & 80.77 \\
\hline
\end{tabular}

Isotopic mass (g/tIHM) - 30 GWD/MT burn-up

\begin{tabular}{|c|c|c|c|c|c|c|c|c|c|}
\hline & \multicolumn{10}{|c|}{ Time Since Discharge (y) } \\
\hline & $\mathbf{0}$ & $\mathbf{2}$ & $\mathbf{5}$ & $\mathbf{1 0}$ & $\mathbf{2 0}$ & $\mathbf{3 0}$ & $\mathbf{5 0}$ & $\mathbf{7 0}$ & $\mathbf{1 0 0}$ \\
\hline${ }^{3} \mathrm{H}$ & 0.118 & 0.106 & 0.089 & 0.067 & 0.038 & 0.022 & 0.0071 & 0.0023 & 0.0004 \\
\hline${ }^{14} \mathrm{C}$ & 0.416 & 0.416 & 0.416 & 0.416 & 0.415 & 0.415 & 0.414 & 0.413 & 0.411 \\
\hline${ }^{85} \mathrm{Kr}$ & 33.79 & 29.71 & 24.49 & 17.74 & 9.314 & 4.889 & 1.347 & 0.371 & 0.054 \\
\hline${ }^{129} \mathrm{I}$ & 127.6 & 127.8 & 127.8 & 127.8 & 127.8 & 127.8 & 127.8 & 127.8 & 127.8 \\
\hline
\end{tabular}

Isotopic mass (g/tIHM) - 60 GWD/MT burn-up

\begin{tabular}{|c|c|c|c|c|c|c|c|r|r|}
\hline & \multicolumn{9}{|c|}{ Time Since Discharge (y) } \\
\hline & $\mathbf{0}$ & $\mathbf{2}$ & $\mathbf{5}$ & $\mathbf{1 0}$ & $\mathbf{2 0}$ & $\mathbf{3 0}$ & $\mathbf{5 0}$ & $\mathbf{7 0}$ & $\mathbf{1 0 0}$ \\
\hline${ }^{3} \mathrm{H}$ & 0.215 & 0.192 & 0.162 & 0.122 & 0.070 & 0.040 & 0.013 & 0.0042 & 0.0008 \\
\hline${ }^{14} \mathrm{C}$ & 0.853 & 0.853 & 0.852 & 0.852 & 0.851 & 0.850 & 0.848 & 0.845 & 0.842 \\
\hline${ }^{85} \mathrm{Kr}$ & 57.67 & 50.71 & 41.79 & 30.28 & 15.89 & 8.343 & 2.299 & 0.634 & 0.092 \\
\hline${ }^{129} \mathrm{I}$ & 278.9 & 279.0 & 279.0 & 279.0 & 279.0 & 279.0 & 279.0 & 279.0 & 279.0 \\
\hline
\end{tabular}

Isotopic mass (g/tIHM) - 100 GWD/MT burn-up

\begin{tabular}{|c|c|c|c|c|c|c|c|c|c|}
\hline & \multicolumn{10}{|c|}{ Time Since Discharge (y) } \\
\hline & $\mathbf{0}$ & $\mathbf{2}$ & $\mathbf{5}$ & $\mathbf{1 0}$ & $\mathbf{2 0}$ & $\mathbf{3 0}$ & $\mathbf{5 0}$ & $\mathbf{7 0}$ & $\mathbf{1 0 0}$ \\
\hline${ }^{3} \mathrm{H}$ & 0.350 & 0.313 & 0.264 & 0.199 & 0.114 & 0.065 & 0.021 & 0.0068 & 0.0013 \\
\hline${ }^{14} \mathrm{C}$ & 1.502 & 1.501 & 1.501 & 1.500 & 1.498 & 1.496 & 1.493 & 1.489 & 1.483 \\
\hline${ }^{85} \mathrm{Kr}$ & 80.32 & 70.61 & 58.20 & 42.17 & 22.13 & 11.62 & 3.202 & 0.882 & 0.128 \\
\hline${ }^{129} \mathrm{I}$ & 490.7 & 490.9 & 490.9 & 490.9 & 490.9 & 490.9 & 490.9 & 490.9 & 490.9 \\
\hline
\end{tabular}

\section{DISPERSION MODELING}

The Clean Air Act Assessment Package (CAP88-PC Version 3.0) computer model (Rosnick 1992) is a set of computer programs, databases, and associated utility programs used to estimate dose and risk to members of the public from radionuclide emissions in the air. Version 3.0 of CAPP-88 incorporates dose and risk factors from Federal Guidance Report 13 (EPA 1999), which are based on the methods of the International Commission on Radiological Protection (ICRP 1995). Emission monitoring and compliance 
procedures for DOE facilities require the use of the CAP- 88 model, or other approved methodologies, to estimate the effective dose to members of the public (Rosnick 2007).

Three main pathways for exposure from an atmospheric release of radiological material are considered in CAP-88: ingestion, inhalation, and external exposure. Ingestion is from consumption of plants, animals, fish, or water contaminated with radionuclides. Inhalation occurs when a person is in the pathway of a gas plume containing radioactive materials. External exposure occurs for people who live or recreate in areas where the ground or water has been exposed to radiological materials. Assessments for collective populations or a maximally exposed individual are possible. Dose and risk estimates from CAP- 88 are applicable only to low-level chronic exposures, since the health effects and dosimetric data are based on low-level chronic intakes. The model cannot be used for either short-term or high-level radionuclide intakes.

\subsection{Input Parameters for CAP-88}

To use the CAP88-PC model, various location-specific, design-specific, and operational parameters are required as input for the simulation. The following were used to form the baseline case:

Facility Data - This input is for general descriptive information of the facility; however, the only information actually used in calculations is the state in which the facility is located. The state parameter determines the appropriate agricultural data (cattle and crop production) to be used in the simulation. Data are available for all states.

Run Options - This input is for an individual or a collective population. The individual option was used in this study so the results could be applied to an assumed MEI.

Meteorological Data - The local average weather conditions are required and include wind characteristics (16 vector description), annual rainfall, average ambient temperature, humidity, and meteorological lid. Calculations performed for each site used meteorological data in the CAP-88 model local to those areas and considered representative of those local areas.

Source Data (Facility Design and Operation) - This input is for the source of the emission. A stack release is assumed for a reprocessing plant, and the data required includes the stack dimensions. The plume type is also required with choices of buoyant or momentum and Pasquill stability class categories for plume rise above stack. The values used for the baseline case are stack height, $36.58 \mathrm{~m}(120 \mathrm{ft})$; stack diameter, $1.5 \mathrm{~m}$; and plume type, Momentum type with stack exit velocity assumed at $18 \mathrm{~m} / \mathrm{s}$ (corresponds to volumetric rate of $34 \mathrm{~m}^{3} / \mathrm{s}$ or $72000 \mathrm{scfm}$ ).

Agricultural Data - This input is used to estimate the uptake of nuclides into the food chain based on agricultural use in the area. Choices are urban, rural, local, regional, or imported. Although values are automatically selected based on the state (location) of the source, the agricultural data can be defined by the user if desired. The rural case was assumed for this study.

Radionuclide Data - This input identifies the nuclides emitted from the source, their emission rate in curies per year, the physical form for some radionuclides (particle, vapor, or organic), and chemical form for some species (tritium, carbon). The vapor form of ${ }^{3} \mathrm{H}$ in tritiated water was assumed; ${ }^{85} \mathrm{Kr}$ form was an unspecified gas; ${ }^{129} \mathrm{I}$ form was particulate; and ${ }^{14} \mathrm{C}$ form was gaseous $\mathrm{CO}_{2}$. 


\section{DETERMINATION OF REQUIRED DFS}

\subsection{Approach Outline}

For this analysis of iodine DF requirements, we use as the basis that the required iodine DF will not be a function of fuel age and that the dose contributions of the short half-life radionuclides will be controlled within allowable discharge limits. However, the iodine DF must be such that there is sufficient "dose headroom" such that the DFs for ${ }^{3} \mathrm{H},{ }^{14} \mathrm{C}$, and ${ }^{85} \mathrm{Kr}$ are also practicable. Thus, we had to consider the potential impacts of the processing of relatively short-cooled fuel to determine those practicable limits. It should be noted that the full analysis of the impacts of fuel age on the DF requirements is the subject of a parallel study that will be reported separately. For each size facility and for each fuel age, the following approach was used to identify DF requirements.

1. Total dose to MEI was determined with CAP-88 (Rosnick 1992) calculations for reference location \#1. This dose assumed no emission controls for the four radionuclides of interest. As a point of interest, we calculated the maximum plant size that would not require emission controls if dose to the maximum exposed individual was the only criteria. This was evaluated for each fuel type and compared to the impact of fuel age and burn-up.

2. Next, for each fuel type and burn-up, we examined a controlled discharge case for dose contribution as a function of fuel age and specific isotope. All of the following steps used a nominal plant used fuel throughput of $1000 \mathrm{t} / \mathrm{y}$.

3. The third step was to apply the computed DF requirement imposed by 40 CFR 190 for ${ }^{85} \mathrm{Kr}$ and

${ }^{129}$ I to meet the fuel cycle curie discharge limits for these two isotopes, assuming the reprocessing facility was the only release point for these isotopes in the complete fuel cycle.

4. We then applied additional recovery factors to reduce the dose to the MEI to the regulatory limits imposed by 40 CFR 190 .

5. This was followed by a determination of the additional DF required, assuming that the dose contribution from the four volatile radionuclides would be limited to $10 \%$ of the dose limit.

6. We then calculated the dose to the thyroid to determine if a higher DF would be required for both the $100 \%$ dose allocation and the $10 \%$ dose allocation.

\subsection{Example Case (PWR UOX - 30 GWD/MTIHM)}

The following is an example case for one fuel type and one burn-up.

Step 1. Calculate whole body dose and maximum plant size requiring no dose-based controls for a fuel type (not yet considering the 40 CFR 190 fuel cycle limits for ${ }^{85} \mathrm{Kr}$ and ${ }^{129} \mathrm{I}$ ). In the case of PWR UOX fuel, the maximum plant size for $30 \mathrm{GWd} / \mathrm{tIHM}$ fuel cooled $5 \mathrm{y}$ is $29.2 \mathrm{t} / \mathrm{y}$; if the fuel is cooled $100 \mathrm{y}$, the plant size is increased slightly to $33.6 \mathrm{t} / \mathrm{y}$ (Figure 4). If the allowable contribution of the volatile components to the total dose is limited to $2.5 \mathrm{mrem} / \mathrm{y}$ (i.e., $10 \%$ of the total dose), the plant sizes drop to $2.9 \mathrm{t} / \mathrm{y}$ and $3.4 \mathrm{t} / \mathrm{y}$, respectively. At 5 y cooling, ${ }^{129} \mathrm{I}$ contributes $86.5 \%$ of the total dose and tritium $12.5 \%$ of the total dose. At 100 y cooling, ${ }^{129}$ I contributes $99.6 \%$ of the total dose. 


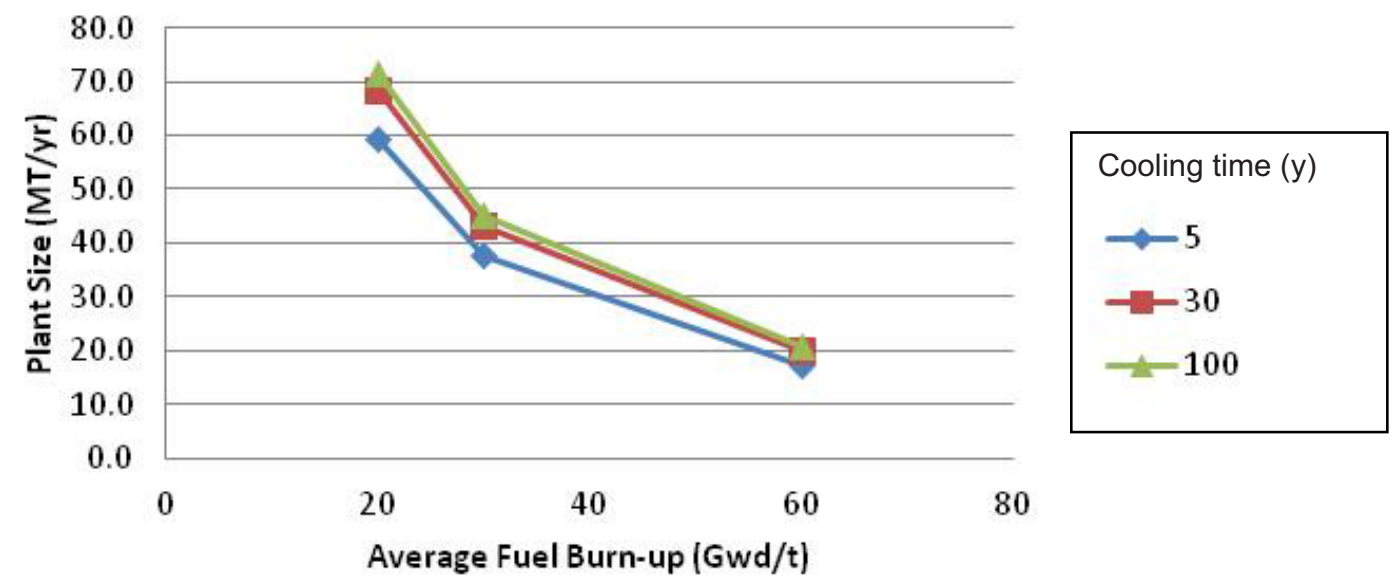

Figure 4. Maximum plant size for processing PWR UOX fuel that would not require controls to limit exposure to the MEI to below $25 \mathrm{mrem} / \mathrm{y}$.

The second phase of the evaluation examined the impact of time since discharge in three steps for each fuel type and fuel burn-up. Now focusing only on the case of $30 \mathrm{GWd} / \mathrm{t}$ burn-up for the detailed calculations of DF requirements:

Step 2. Calculate uncontrolled dose contributions. For the case of the $30 \mathrm{GWd} / \mathrm{tIHM}$ fuel and a plant size of $1000 \mathrm{t} / \mathrm{y}$, the total dose to the MEI ranges from $686 \mathrm{mrem} / \mathrm{y}$ at 2-y-cooled fuel to $553 \mathrm{mrem} / \mathrm{y}$ at $100 \mathrm{y}$ cooled (Figure 5). Iodine is the major contributor (550 mrem/y). At cooling times up to $30 \mathrm{y}$, tritium dose contributions exceed $25 \mathrm{mrem} / \mathrm{y} ;{ }^{14} \mathrm{C}$ contributes $2.6 \mathrm{mrem} / \mathrm{y}$ at all cooling times; and ${ }^{85} \mathrm{Kr}$ could contribute up to $6 \mathrm{mrem} / \mathrm{y}$ at short cooling times. Uncontrolled dose contributions by isotope are presented in Table 7.

Step 3. Apply 40 CFR 190 curie release limits. If the iodine and krypton release limits imposed by 40 CFR 190 are then applied to these values, the whole body dose to the MEI is reduced to $134 \mathrm{mrem} / \mathrm{y}$ at $2 \mathrm{y}$ cooling and $6.24 \mathrm{mrem} / \mathrm{y}$ for $100-\mathrm{y}$-cooled fuel (Figure 6). The iodine contribution is reduced to $3.15 \mathrm{mrem} / \mathrm{y}$, and ${ }^{3} \mathrm{H}$ becomes the major contributor at cooling times less than $50 \mathrm{y}$. Carbon- 14 again contributes $2.6 \mathrm{mrem} / \mathrm{y}$, but ${ }^{85} \mathrm{Kr}$ contributions are reduced to less than $0.8 \mathrm{mrem} / \mathrm{y}$. It is clear from Figure 6 that additional controls at least on ${ }^{3} \mathrm{H}$ would be required to meet a $25 \mathrm{mrem} / \mathrm{y}$ limit. Figure 7 shows that for a $2.5 \mathrm{mrem} / \mathrm{y}$ apportioned limit, additional controls (DF) for iodine would also be required (note that the allowable $[2.5 \mathrm{mrem} / \mathrm{y}]$ and ${ }^{14} \mathrm{C}[2.6 \mathrm{mrem} / \mathrm{y}]$ lines are superimposed because of the scale of the graph). 


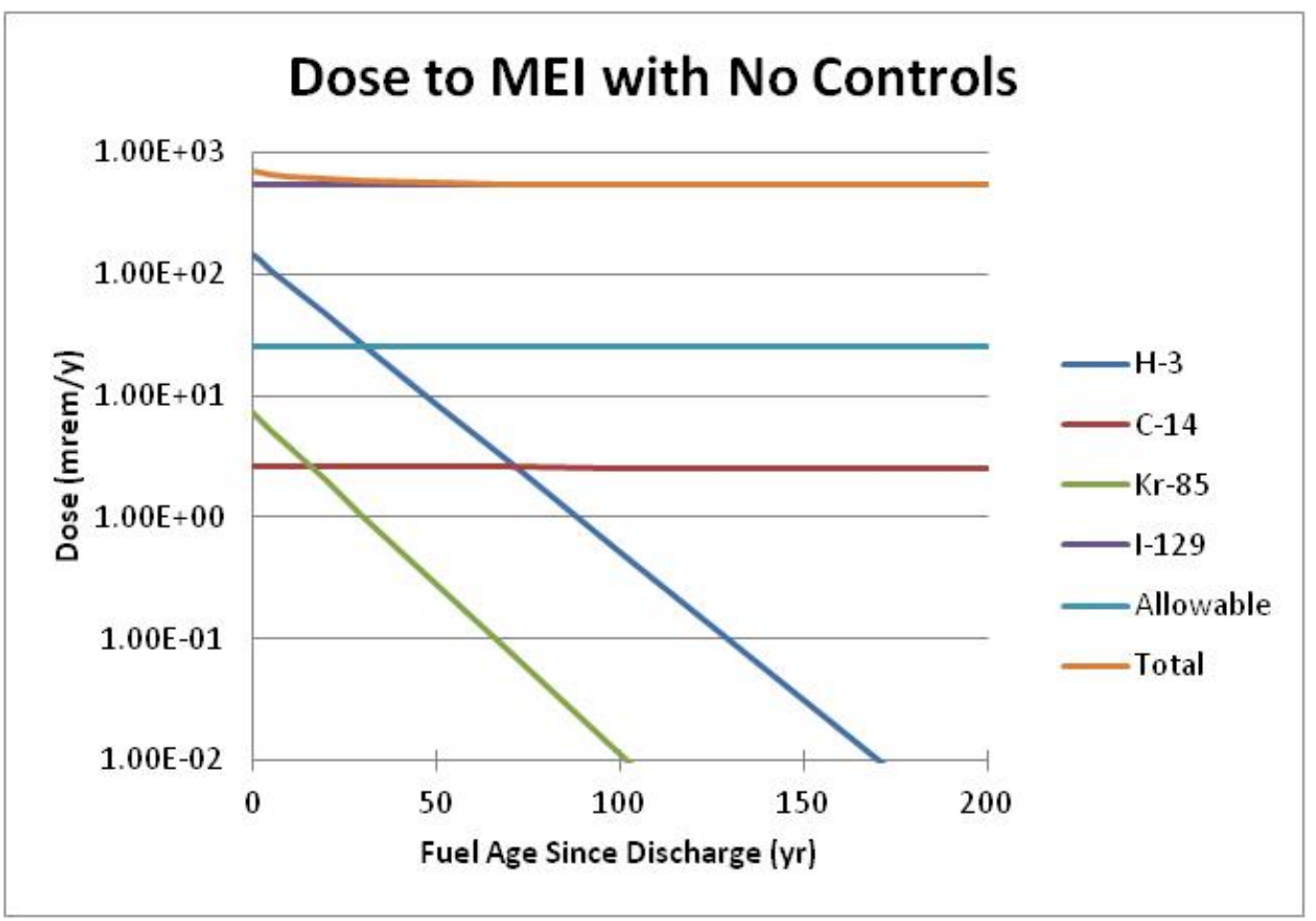

Figure 5. Total whole body dose and dose contributions arising from uncontrolled volatile radionuclides to the MEI from a 1000 t/y recycle plant processing 30 GWd/tIHM PWR UOX fuel. Allowable dose limit is shown at the $25 \mathrm{mrem} / \mathrm{y}$ whole body dose level.

Table 7. Dose contributions (mrem/y) by radionuclide based on 30 GWd/tIHM PWR UOX fuel cooled up to $200 \mathrm{y}$ and processed in a $1000 \mathrm{t} / \mathrm{y}$ recycle plant without effluent controls

\begin{tabular}{|c|c|c|c|c|c|c|c|c|c|c|}
\hline & \multicolumn{9}{|c|}{ Years after reactor discharge } \\
\hline Isotope & $\mathbf{0}$ & $\mathbf{2}$ & $\mathbf{5}$ & $\mathbf{1 0}$ & $\mathbf{2 0}$ & $\mathbf{3 0}$ & $\mathbf{5 0}$ & $\mathbf{7 0}$ & $\mathbf{1 0 0}$ & $\mathbf{2 0 0}$ \\
\hline${ }^{3} \mathrm{H}$ & 142 & 127 & 107 & 81.1 & 46.2 & 26.4 & 8.56 & 2.78 & 0.52 & 0.0019 \\
\hline${ }^{14} \mathrm{C}$ & 2.60 & 2.60 & 2.60 & 2.60 & 2.59 & 2.59 & 2.58 & 2.58 & 2.57 & 2.54 \\
\hline${ }^{85} \mathrm{Kr}$ & 7.19 & 6.32 & 5.20 & 3.77 & 1.97 & 1.03 & 0.28 & 0.078 & 0.011 & 0.000017 \\
\hline${ }^{129} \mathrm{I}$ & 550 & 550 & 550 & 550 & 550 & 550 & 550 & 550 & 550 & 550 \\
\hline Allowable & 25 & 25 & 25 & 25 & 25 & 25 & 25 & 25 & 25 & 25 \\
\hline Total & $\mathbf{7 0 2}$ & $\mathbf{6 8 6}$ & $\mathbf{6 6 6}$ & $\mathbf{6 3 8}$ & $\mathbf{6 0 1}$ & $\mathbf{5 8 0}$ & $\mathbf{5 6 2}$ & $\mathbf{5 5 6}$ & $\mathbf{5 5 3}$ & $\mathbf{5 5 3}$ \\
\hline
\end{tabular}




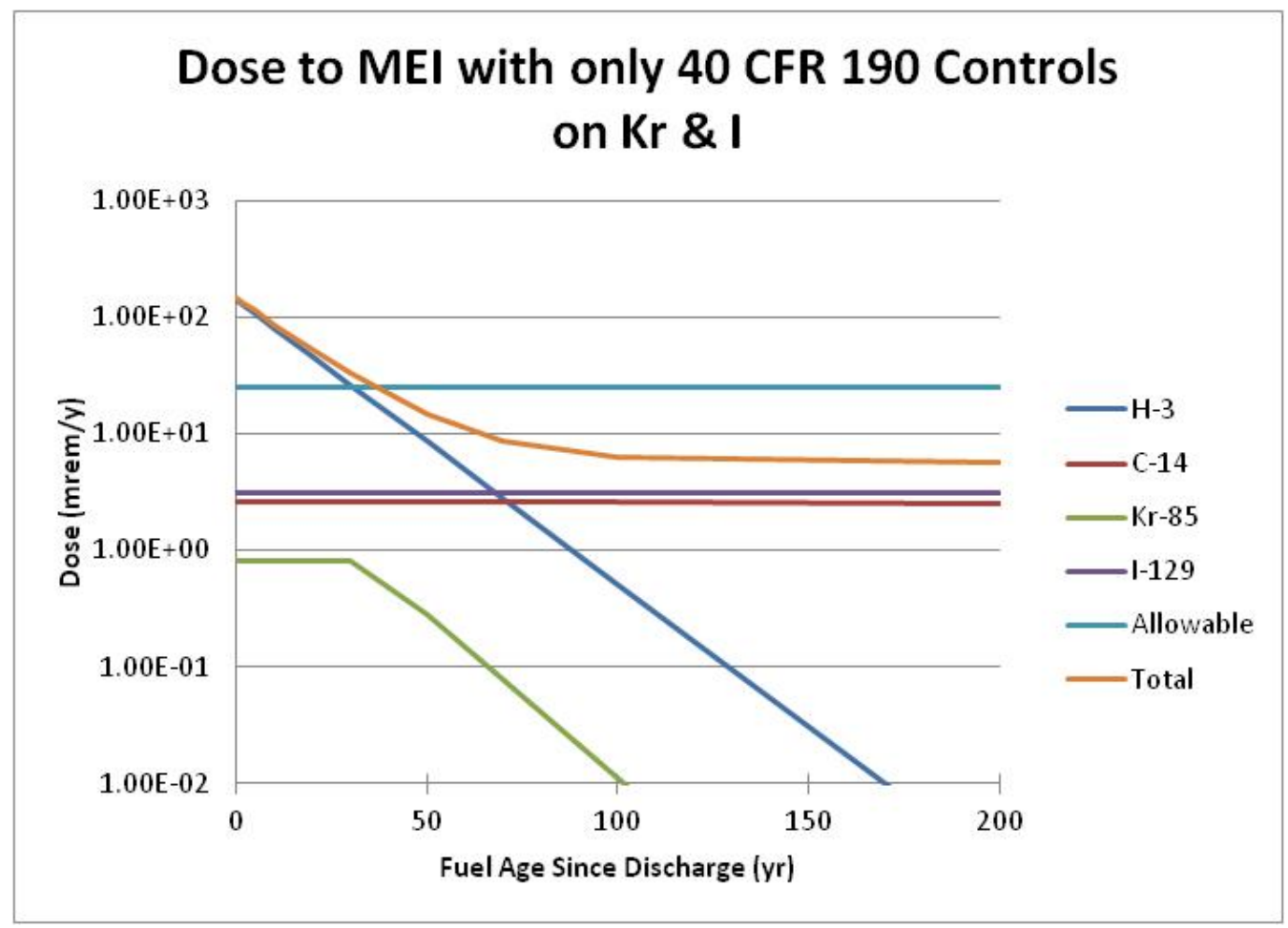

Figure 6. Total whole body dose and dose contributions arising from volatile radionuclides to the MEI from a 1000 t/y recycle plant processing $30 \mathrm{GWd} /$ tIHM PWR UOX fuel with iodine and krypton controls per 40 CFR 190. Allowable dose limit is shown at the $25 \mathrm{mrem} / \mathrm{y}$ whole body dose level. 


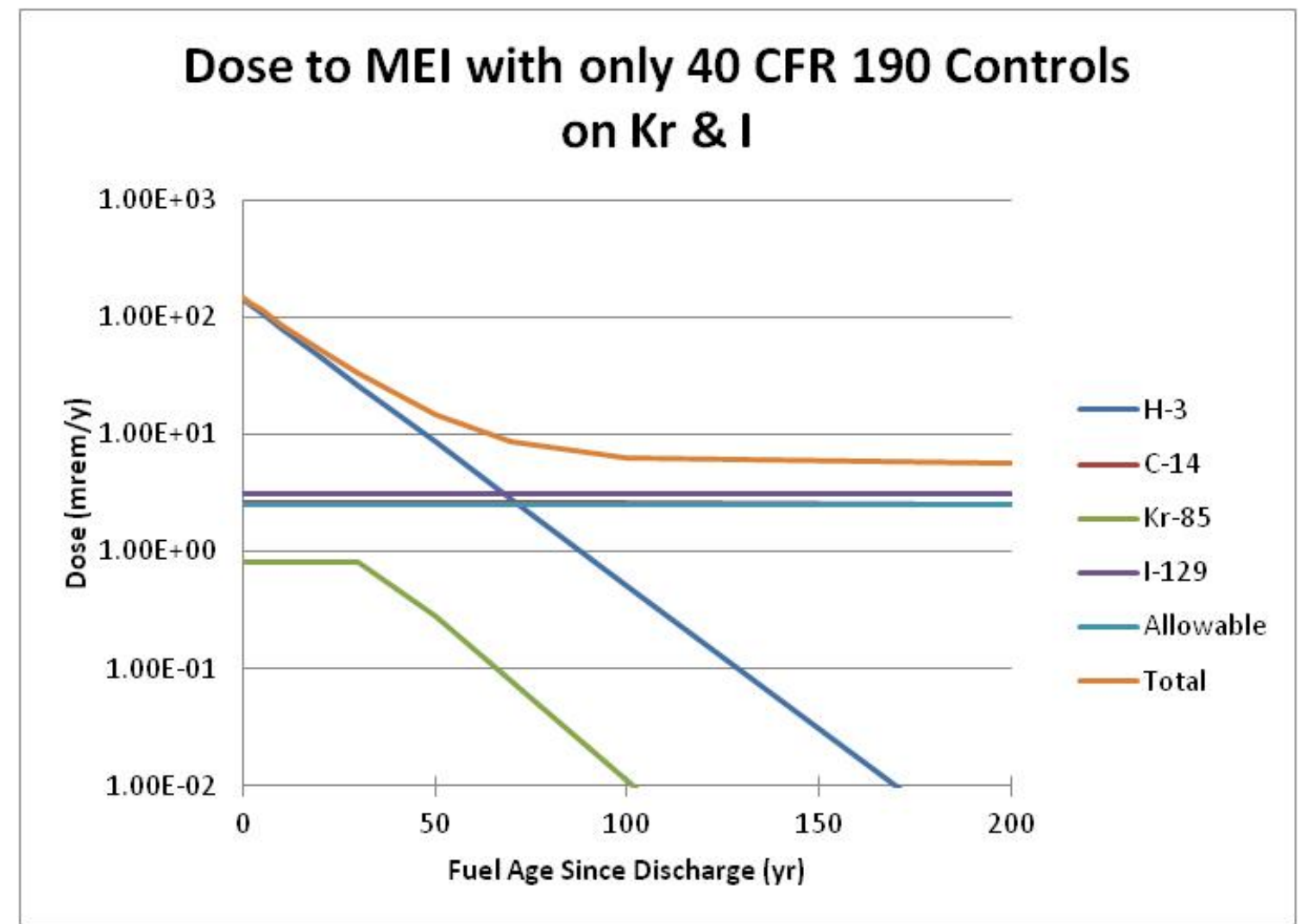

Figure 7. Total whole body dose and dose contributions arising from volatile radionuclides to the MEI from a $1000 \mathrm{t} / \mathrm{y}$ recycle plant processing $30 \mathrm{GWd} / \mathrm{tIHM}$ PWR UOX fuel with iodine and krypton controls per 40 CFR 190. Allowable dose limit is shown at the $2.5 \mathrm{mrem} / \mathrm{y}$ whole body dose level.

Steps 4 \& 5. Apply additional DF requirements as needed to limit dose to MEI to regulatory limits. Additional controls were imposed as needed on individual isotopes in order to reduce the calculated emissions to the extent required to reduce the dose to the MEI to the regulatory limit or to a portion of the regulatory limit. In general, we attempted to impose control on as few individual radionuclides as possible, since each would likely require a separate process to control and result in a separate waste stream that would need treatment. In selecting the required DF, there is no single correct answer, since the total dose is a sum of the individual contributions. The reduction in one allows more "headroom" for another. A nominal goal was to reduce the dose contribution from an individual radionuclide to somewhere in the range of $10-50 \%$ of the total allowable dose. Additional controls were applied first to species that exceeded the allowable limits. For ${ }^{3} \mathrm{H}$ and ${ }^{85} \mathrm{Kr}$, these were typically applied over the periods of fuel age in which the dose contributions exceeded $30-50 \%$ of the allowable dose. Additional controls were typically added to ${ }^{129} \mathrm{I}$ before ${ }^{14} \mathrm{C}$, since ${ }^{129} \mathrm{I}$ control would be required in all cases anyway.

For the $25 \mathrm{mrem} / \mathrm{y}$ limit case, additional controls were imposed for ${ }^{3} \mathrm{H}$. Tritium DF requirements ranged from 6.9 at $2 \mathrm{y}$ cooling to 1.43 at $30 \mathrm{y}$ cooling (Figure 8 and Table 8 ). Beyond $\sim 35 \mathrm{y}$ fuel cooling, no additional ${ }^{3} \mathrm{H}$ capture would be required if the total dose to the MEI from ${ }^{3} \mathrm{H},{ }^{14} \mathrm{C},{ }^{85} \mathrm{Kr}$, and ${ }^{129} \mathrm{I}$ were taken into account. If these four radionuclides are apportioned $2.5 \mathrm{mrem} / \mathrm{y}$ or $10 \%$ of the allowable dose, then additional controls must be placed on ${ }^{14} \mathrm{C}$ and ${ }^{129} \mathrm{I}$ for all fuel ages, since these individually contribute more than $2.5 \mathrm{mrem} / \mathrm{y}$ and ${ }^{3} \mathrm{H}$ contributes more than $2.5 \mathrm{mrem} / \mathrm{y}$ until the fuel is aged over $70 \mathrm{y}$. An additional recovery factor of 10 was applied to ${ }^{129}$ I for all fuel ages, raising the total ${ }^{129}$ I DF to $\sim 1200$. A ${ }^{14} \mathrm{C}$ DF of 3 was applied to reduce its contribution to the total dose to $\sim 0.8 \mathrm{mrem} / \mathrm{y}$. Tritium DFs of 250 would be required for 2-y-cooled fuel. Beyond $\sim 80 \mathrm{y}$, no ${ }^{3} \mathrm{H}$ recovery would be required. Figure 9 shows 
the resulting total dose to the MEI and the individual dose contributions as a function of time. Figure 10 depicts the DF requirements for each isotope as a function of cooling time. Table 9 shows the overall DF required to limit the dose to the MEI to $2.5 \mathrm{mrem} / \mathrm{y}$, and Table 10 shows the resulting dose contributions.

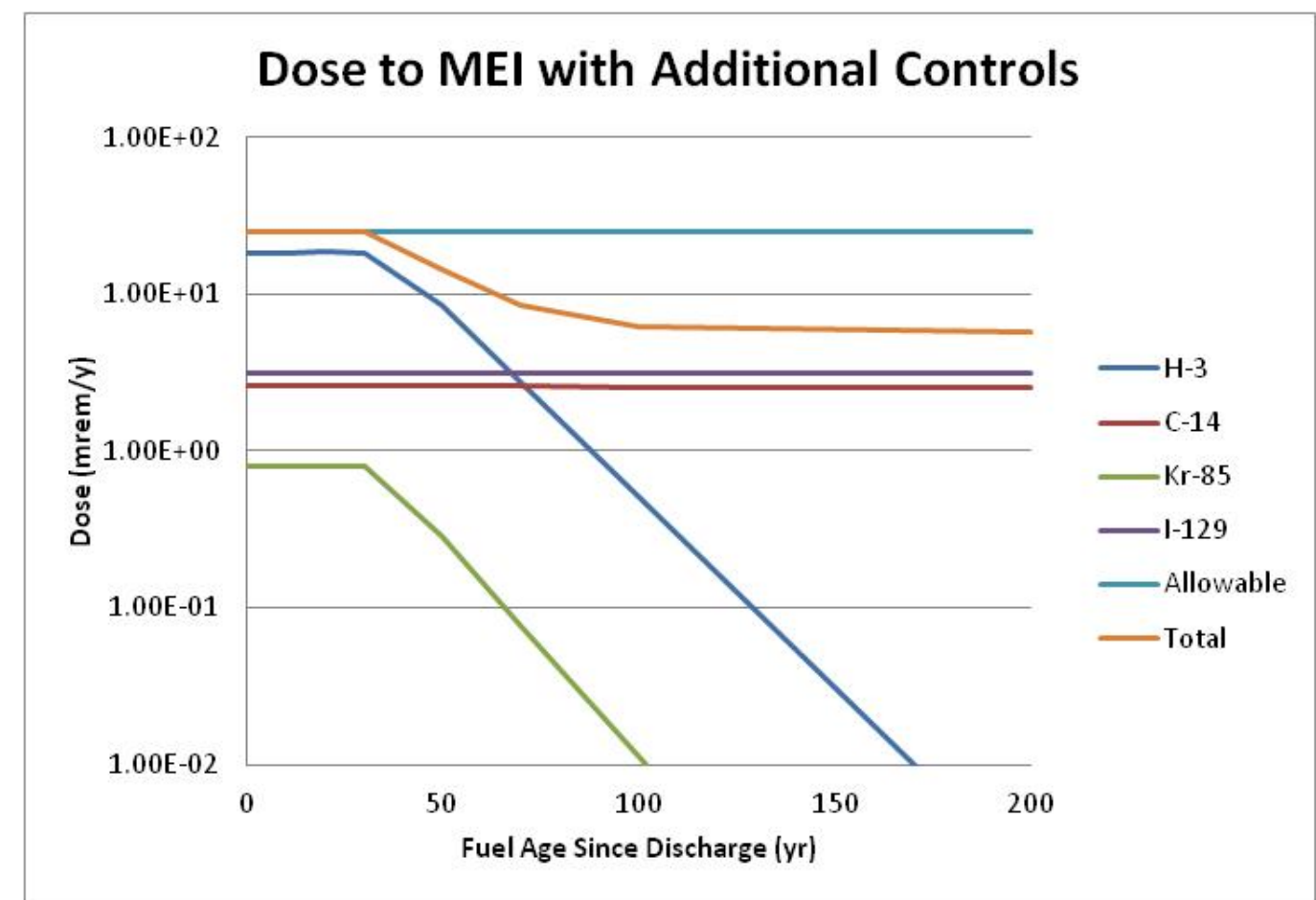

Figure 8. Dose to MEI total and dose contribution from each of the volatile radionuclides, as a function of fuel age for a $1000 \mathrm{t} / \mathrm{y}$ recycle plant processing $30 \mathrm{GWd} / \mathrm{tIHM}$ PWR UOX fuel. Controls are implemented to meet the 40 CFR 190 fuel cycle limits and the $25 \mathrm{mrem} / \mathrm{y}$ whole body dose limit.

Table 8. Effective DFs required to achieve $25 \mathrm{mrem} / \mathrm{y}$ whole body dose to MEI for $30 \mathrm{GWd} / \mathrm{tIHM}$ PWR UOX fuel processed in a $1000 \mathrm{t} / \mathrm{y}$ facility

\begin{tabular}{|c|c|c|c|c|c|c|c|c|c|c|}
\hline \multirow[b]{2}{*}{ Isotope } & \multicolumn{10}{|c|}{ Fuel Age, y } \\
\hline & 0 & 2 & 5 & 10 & 20 & 30 & 50 & 70 & 100 & 200 \\
\hline${ }^{3} \mathrm{H}$ & 7.72 & 6.90 & 5.83 & 4.40 & 2.50 & 1.43 & 1.00 & 1.00 & 1.00 & 1.00 \\
\hline${ }^{14} \mathrm{C}$ & 1.00 & 1.00 & 1.00 & 1.00 & 1.00 & 1.00 & 1.00 & 1.00 & 1.00 & 1.00 \\
\hline${ }^{85} \mathrm{Kr}$ & 8.91 & 7.83 & 6.45 & 4.67 & 2.44 & 1.28 & 1.00 & 1.00 & 1.00 & 1.00 \\
\hline${ }^{129} \mathrm{I}$ & 175 & 175 & 175 & 175 & 175 & 175 & 175 & 175 & 175 & 175 \\
\hline
\end{tabular}




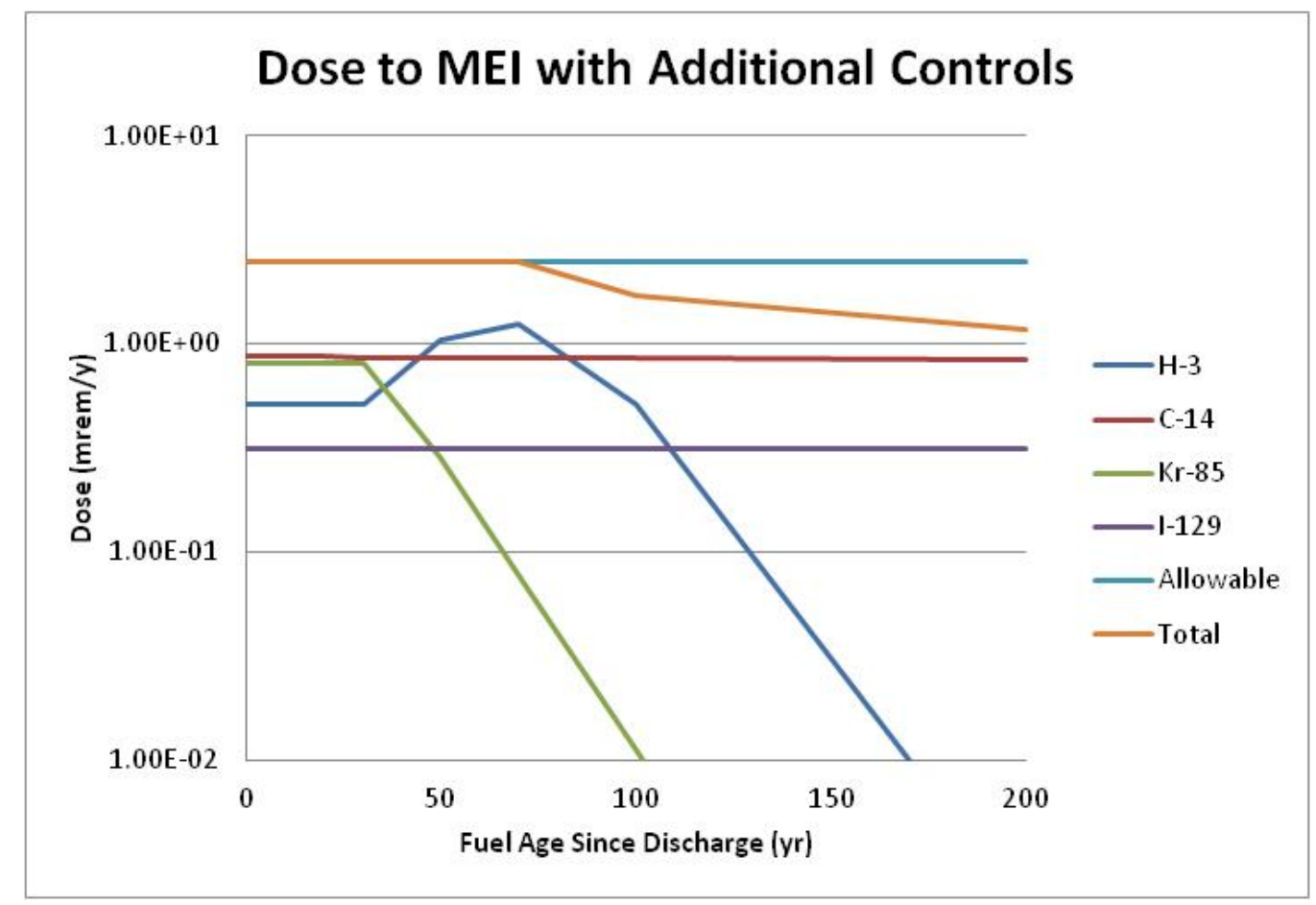

Figure 9. Dose to MEI total and dose contribution from each of the volatile radionuclides, as a function of fuel age for a $1000 \mathrm{t} / \mathrm{y}$ recycle plant processing $30 \mathrm{GWd} / \mathrm{tIHM}$ PWR UOX fuel. Controls are implemented to meet the 40 CFR 190 fuel cycle limits and to meet an allowable whole body dose limit at $2.5 \mathrm{mrem} / \mathrm{y}$.

Table 9. Effective DFs required to achieve $2.5 \mathrm{mrem} / \mathrm{y}$ dose to MEI for $30 \mathrm{GWd} / \mathrm{tIHM}$ PWR UOX fuel processed in a $1000 \mathrm{t} / \mathrm{y}$ facility

\begin{tabular}{|l|c|c|c|c|c|c|c|c|c|c|}
\hline & \multicolumn{10}{|c|}{ Fuel Age, $\mathbf{y}$} \\
\cline { 2 - 10 } Isotope & $\mathbf{0}$ & $\mathbf{2}$ & $\mathbf{5}$ & $\mathbf{1 0}$ & $\mathbf{2 0}$ & $\mathbf{3 0}$ & $\mathbf{5 0}$ & $\mathbf{7 0}$ & $\mathbf{1 0 0}$ & $\mathbf{2 0 0}$ \\
\hline${ }^{3} \mathrm{H}$ & 280 & 250 & 210 & 158 & 90.0 & 51.0 & 8.20 & 2.23 & 1.00 & 1.00 \\
${ }^{14} \mathrm{C}$ & 3.00 & 3.00 & 3.00 & 3.00 & 3.00 & 3.00 & 3.00 & 3.00 & 3.00 & 3.00 \\
${ }^{85} \mathrm{Kr}$ & 8.91 & 7.83 & 6.45 & 4.67 & 2.44 & 1.28 & 1.00 & 1.00 & 1.00 & 1.00 \\
${ }^{129} \mathrm{I}$ & 1749 & 1749 & 1749 & 1749 & 1749 & 1749 & 1749 & 1749 & 1749 & 1749 \\
\hline
\end{tabular}


Table 10. Dose contributions (mrem/y) by radionuclide based on $30 \mathrm{GWD} / \mathrm{tIHM}$, PWR UOX fuel cooled up to $200 \mathrm{y}$ with the effective DFs from Table 10

\begin{tabular}{|c|c|c|c|c|c|c|c|c|c|c|}
\hline \multirow[b]{2}{*}{ Isotope } & \multicolumn{10}{|c|}{ Fuel Age, y } \\
\hline & 0 & 2 & 5 & 10 & 20 & 30 & 50 & 70 & 100 & 200 \\
\hline${ }^{3} \mathrm{H}$ & 0.51 & 0.51 & 0.51 & 0.51 & 0.51 & 0.52 & 1.04 & 1.25 & 0.52 & 0.0019 \\
\hline${ }^{14} \mathrm{C}$ & 0.87 & 0.87 & 0.87 & 0.87 & 0.87 & 0.86 & 0.86 & 0.86 & 0.86 & 0.85 \\
\hline${ }^{85} \mathrm{Kr}$ & 0.81 & 0.81 & 0.81 & 0.81 & 0.81 & 0.81 & 0.28 & 0.078 & 0.011 & 0.000017 \\
\hline${ }^{129} \mathrm{I}$ & 0.31 & 0.31 & 0.31 & 0.31 & 0.31 & 0.31 & 0.31 & 0.31 & 0.31 & 0.31 \\
\hline Allowable & 2.5 & 2.5 & 2.5 & 2.5 & 2.5 & 2.5 & 2.5 & 2.5 & 2.5 & 2.5 \\
\hline Total & 2.5 & 2.5 & 2.5 & 2.5 & 2.5 & 2.5 & 2.5 & 2.5 & 1.70 & 1.16 \\
\hline
\end{tabular}

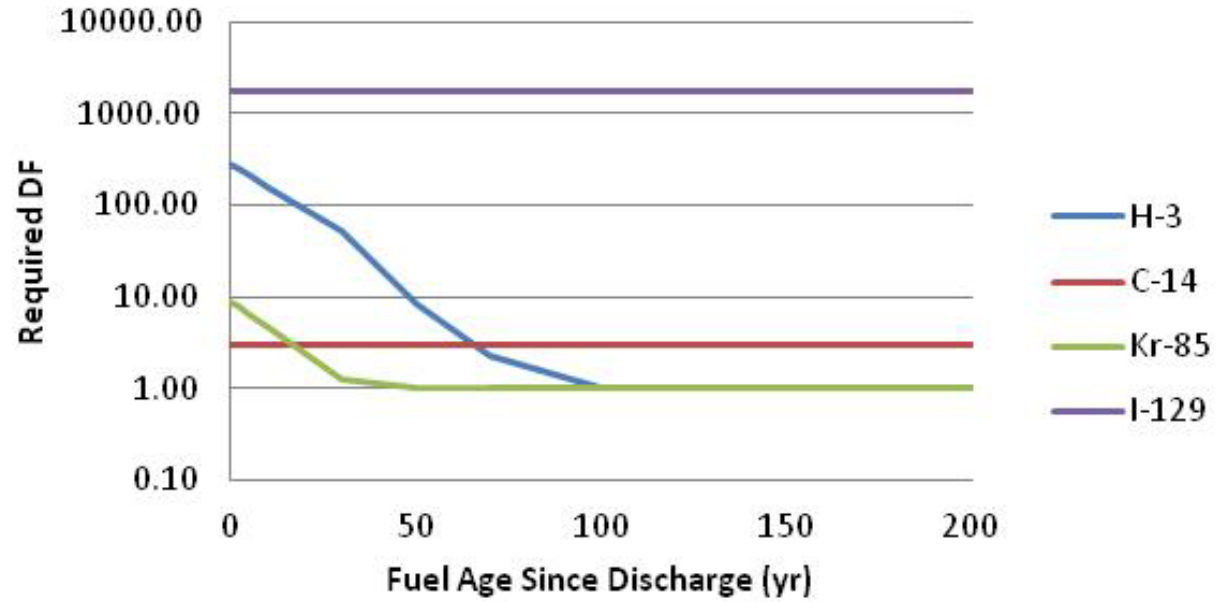

Figure 10. Required DFs for each of the volatile radionuclides, as a function of fuel age for a $1000 \mathrm{t} / \mathrm{y}$ recycle plant processing 30 GWd/tIHM PWR UOX fuel. Controls are implemented to meet the $40 \mathrm{CFR} 190$ fuel cycle limits and to meet an allowable dose limit at $2.5 \mathrm{mrem} / \mathrm{y}$.

Step 6. Calculate thyroid dose. In addition to meeting the whole body dose, there are limits to specific organs. The dose limit to the thyroid is specified in 40 CFR 190 as $75 \mathrm{mrem} / \mathrm{y}$. Applying the same DFs previously used to meet the 40 CFR $190 \mathrm{Ci}$ discharge limits for only I and $\mathrm{Kr}$ reduces the thyroid dose to $129 \mathrm{mrem} / \mathrm{y}$ for the processing of 2-y-cooled fuel and to $65.6 \mathrm{mrem} / \mathrm{y}$ for 100 -y-cooled fuel (Figure 11). The two primary contributors to the dose are ${ }^{3} \mathrm{H}$ and ${ }^{129} \mathrm{I}$ in the case of short cooling times. 


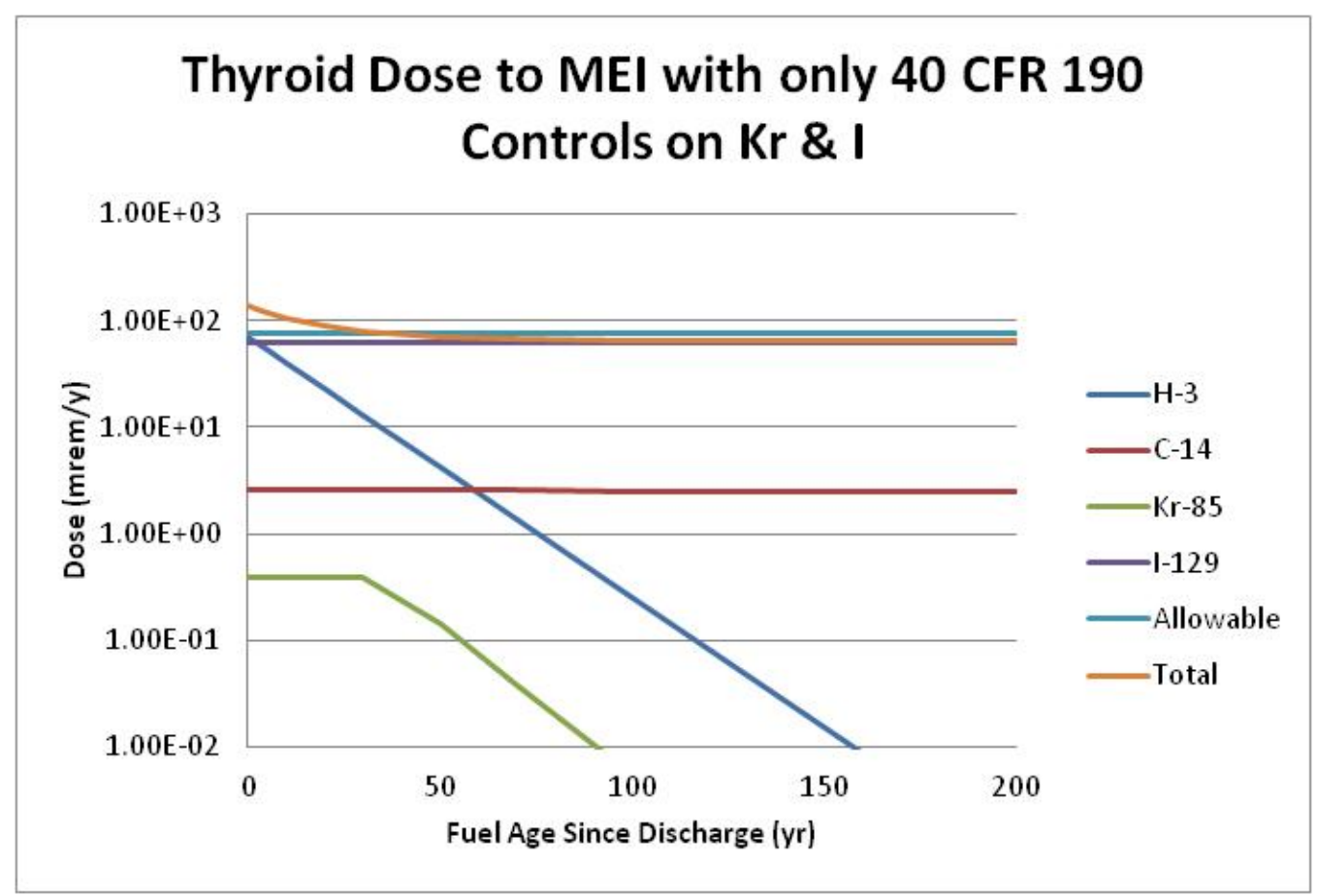

Figure 11. Dose to the thyroid and dose contribution from each of the volatile radionuclides, as a function of fuel age for a $1000 \mathrm{t} / \mathbf{y}$ recycle plant processing $30 \mathrm{GWd} / \mathrm{tIHM}$ PWR UOX fuel. Controls are implemented to meet the 40 CFR 190 curie release limits. Allowable thyroid dose shown is $75 \mathrm{mrem} / \mathrm{y}$.

Now, applying the same additional DF requirements as imposed to meet the whole body dose limit of $25 \mathrm{mrem} / \mathrm{y}$, the thyroid dose calculations show that dose to the thyroid is reduced to $74.8 \mathrm{mrem} / \mathrm{y}$. Thus, no additional DF requirement would be needed beyond those needed to meet the $25 \mathrm{mrem} / \mathrm{y}$ whole body dose limit (Figure 12).

If the same apportionment of $10 \%$ is made for the thyroid dose from the four volatile radionuclides as for the whole body dose and if the some additional controls are applied, the resulting thyroid dose is 7.78$7.38 \mathrm{mrem} / \mathrm{y}$ (Figure 13). Iodine-129 accounts for approximately $\sim 80 \%$ of this dose, with ${ }^{14} \mathrm{C}$ the major contributor to the remaining dose. A slight increase in the ${ }^{129}$ I DF from $\sim 1750$ to 1850 is required to reduce the thyroid dose to $<7.5 \mathrm{mrem} / \mathrm{y}$, holding the DFs for the other isotopes as they were. 


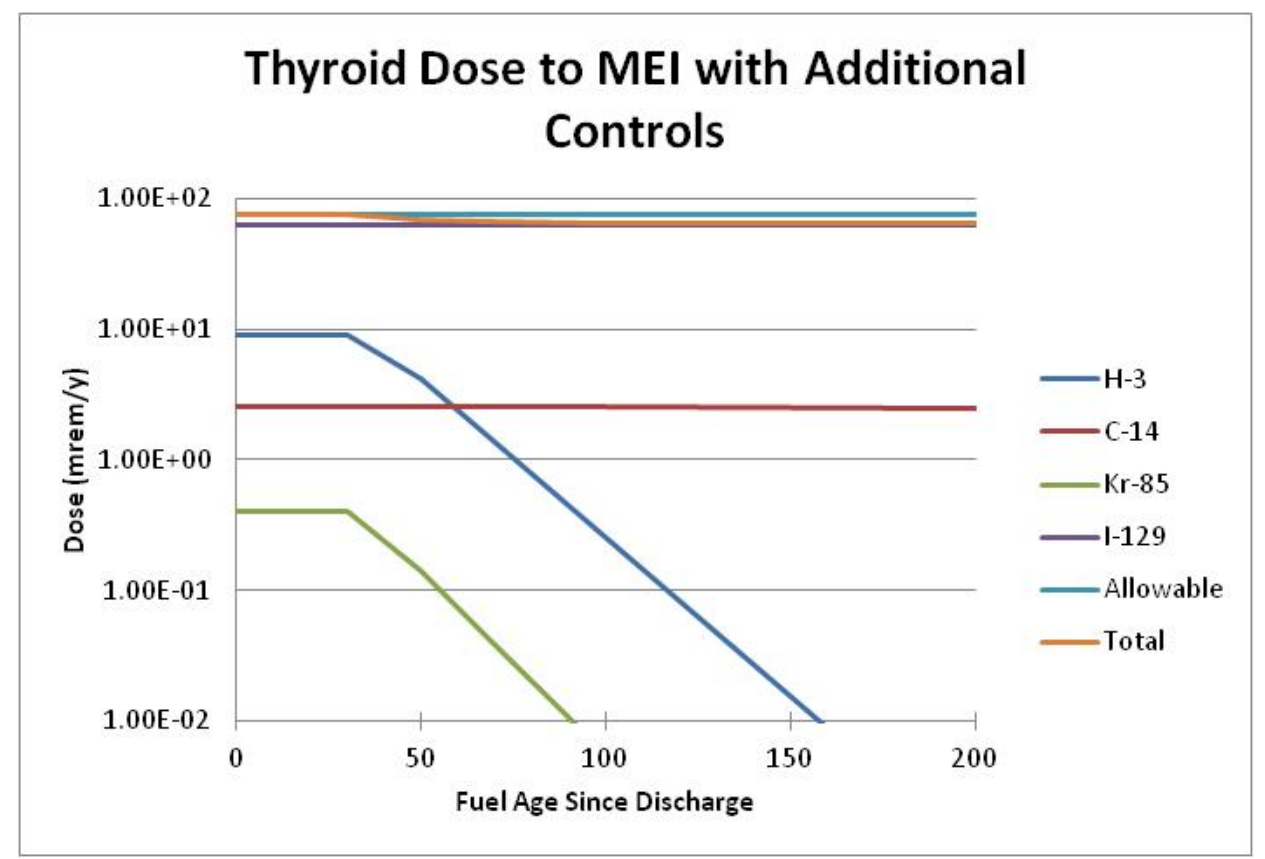

Figure 12. Dose to the thyroid and thyroid dose contribution from each of the volatile radionuclides, as a function of fuel age for a $1000 \mathrm{t} / \mathrm{y}$ recycle plant processing $30 \mathrm{GWd} / \mathrm{tIHM}$ PWR UOX fuel. Controls are implemented to meet the 40 CFR190 curie release limits and the $25 \mathrm{mrem} / \mathrm{y}$ whole body dose limit. Allowable thyroid dose shown is $75 \mathrm{mrem} / \mathrm{y}$.

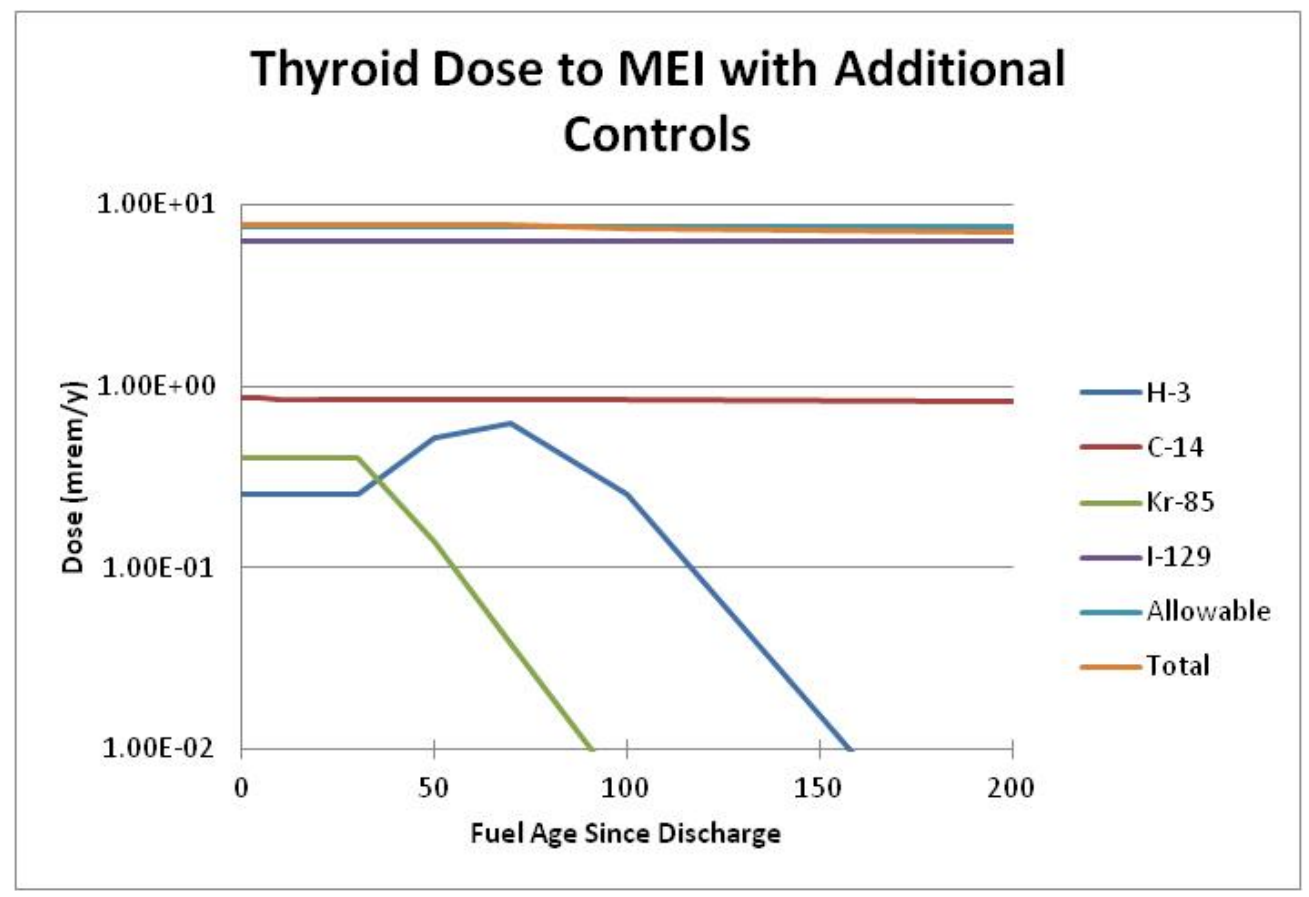

Figure 13. Dose to the thyroid and dose contribution from each of the volatile radionuclides, as a function of fuel age for a $1000 \mathrm{t} / \mathrm{y}$ recycle plant processing $30 \mathrm{GWd} / \mathbf{t I H M}$ PWR UOX fuel. Controls are implemented to meet the 40 CFR190 curie release limit and additional controls required to meet an allocated $2.5 \mathrm{mrem} / \mathrm{y}$ whole body dose limit, and an allocated thyroid dose limit of $7.5 \mathrm{mrem} / \mathrm{y}$. Allowable thyroid dose shown is $7.5 \mathrm{mrem} / \mathrm{y}$. 


\subsection{Summary of Results for PWR UOX Fuel}

Tables 11 and 12 summarize the DF requirements for the capture of volatile radionuclides from the processing of PWR UOX fuel with burn-ups ranging from 20 to $60 \mathrm{GWd}$ /tIHM. This assumes a nominal plant throughput of $1000 \mathrm{t} / \mathrm{y}$. The results shown in Table 11 consider the case where the dose to the MEI only is attributable to the volatile radionuclides. This provides the smallest DF that would be required, based on the assumptions and inputs to the CAP- 88 air dispersion and dose model. (Again note that no engineering margins are included in these values.) For low burn-up fuel the dose to the whole body is the limiting dose factor, but as the burn-up increases, the thyroid dose becomes limiting. Controls for ${ }^{3} \mathrm{H}$ and ${ }^{85} \mathrm{Kr}$ are required for shorter-cooled fuels, up to $\sim 60 \mathrm{y}$ cooling. No controls are required on ${ }^{14} \mathrm{C}$. Iodine DFs ranging from 166 to 380, depending on fuel burn-up, would be required for any fuel cooling time.

The results shown in Table 12 are based on the allocation of $10 \%$ of the dose limit being attributed to the volatile radionuclides. For only the lowest burn-up fuel $(20 \mathrm{GWd} / \mathrm{tIHM})$ is the dose to the whole body the limiting dose factor. For higher fuel burn-ups the thyroid dose is the limiting case. Iodine DFs range from 1660 to 3800, depending on fuel burn-up, for all cooling times. Iodine DF increases with fuel burn-up. Depending on the burn-up of the fuel and fuel age, additional controls are required for some or all of the other volatile radionuclides. For short fuel cooling times, more controls are required, and the higher DFs are associated with these shorter-cooled fuels.

Table 11. A summary of DF requirements for the processing of PWR UOX in a 1000 t/y facility

(For these data, $100 \%$ of the dose to the MEI is allocated to volatile radionuclides.)

\begin{tabular}{|c|c|c|c|c|c|}
\hline \multirow[b]{2}{*}{$\begin{array}{c}\text { Burn-up } \\
\text { (GWd/tIHM) }\end{array}$} & \multirow{2}{*}{$\begin{array}{c}\text { Most Restrictive Dose Limit } \\
\text { (25 mrem/y Whole Body; } \\
75 \mathrm{mrem} / \mathrm{y} \text { Thyroid })\end{array}$} & \multicolumn{4}{|c|}{ Required DF to Meet Dose Limit } \\
\hline & & ${ }^{3} \mathbf{H}^{\mathrm{a}}$ & ${ }^{14} \mathrm{C}$ & ${ }^{85} \mathrm{Kr}^{\mathbf{a}}$ & ${ }^{129} \mathbf{I}$ \\
\hline 20 & Whole Body & $3.85-1$ & 1 & $8.84-1$ & 166 \\
\hline 30 & Whole Body & $6.9-1$ & 1 & $7.83-1$ & 175 \\
\hline 60 & Thyroid & $25-1$ & 1 & $6.16-1$ & 380 \\
\hline
\end{tabular}

${ }^{\mathrm{a}}$ These are ranges depending on the fuel burn-up, i.e., $3.85-1$ is the range from 3.85 to 1 .

Table 12. A summary of DF requirements for the processing of PWR UOX in a $1000 \mathrm{t} / \mathrm{y}$ facility

For these data, $10 \%$ of the dose to the MEI allocated to volatile radionuclides

\begin{tabular}{|c|l|c|c|c|c|}
\hline & Most Restrictive Dose Limit & \multicolumn{4}{|c|}{ Required DF to Meet Dose Limit } \\
\cline { 4 - 6 } $\begin{array}{c}\text { Burn-up } \\
\text { (GWd/tIHM) }\end{array}$ & $\begin{array}{c}(2.5 \mathrm{mrem} / \mathrm{y} \text { Whole Body; } \\
7.5 \mathrm{mrem} / \mathrm{y} \text { Thyroid) }\end{array}$ & ${ }^{\mathbf{3}} \mathbf{H}^{\mathbf{a}}$ & ${ }^{14} \mathbf{C}$ & ${ }^{\mathbf{8 5}} \mathbf{K r}^{\mathbf{a}}$ & ${ }^{129} \mathbf{I}$ \\
\hline 20 & Whole Body & $225-1$ & 1 & $17.9-1$ & 1660 \\
\hline 30 & Thyroid & $250-1$ & 3 & $7.83-1$ & 1850 \\
\hline 60 & Thyroid & $600-1$ & 10 & $12.32-1$ & 3800 \\
\hline
\end{tabular}

${ }^{\mathrm{a}}$ These are ranges depending on the fuel burn-up, i.e., $3.85-1$ is the range from 3.85 to 1 . 


\subsection{Summary of Results for PWR MOX Fuel}

Tables 13 and 14 summarize the DF requirements for the capture of the volatile radionuclides from processing PWR MOX fuel with burn-ups ranging from 20 to $100 \mathrm{GWd} / \mathrm{tIHM}$. This assumes the nominal plant throughput of $1000 \mathrm{t} / \mathrm{y}$. Table 13 considers the case where the dose to the MEI only is attributable to the volatile radionuclides. This provides the smallest DF that would be required, based on the assumptions and inputs to the CAP-88 air dispersion and dose model. (Again note that no engineering margins are included in these values.) For low burn-up fuel the dose to the whole body is the limiting dose factor, but as the burn-up increases, the thyroid dose becoming limiting. Controls for ${ }^{3} \mathrm{H}$ and ${ }^{85} \mathrm{Kr}$ are required for shorter-cooled fuels, up to $\sim 80$ y cooling. No controls are required on ${ }^{14} \mathrm{C}$. Iodine DFs ranging from 279 to 630 , depending on fuel burn-up, would be required for any fuel cooling time.

Table 14 is based on the allocation of $10 \%$ of the dose limit being attributed to the volatile radionuclides. For only the lowest burn-up fuel $(20 \mathrm{GWd} / \mathrm{tIHM})$ is the dose to the whole body the limiting dose factor. For higher fuel burn-ups, the thyroid dose is the limiting case. Iodine DFs range from 2800 to 8000 , depending on fuel burn-up, for all cooling times. Iodine DFs increase with fuel burn-up. Depending on the burn-up of the fuel and fuel age, additional controls will be required for most or all of the other volatile radionuclides. For short fuel cooling times, more controls are required, and the higher DFs are associated with these shorter-cooled fuels.

Table 13. A summary of DF requirements for the processing of PWR MOX in a $1000 \mathrm{t} / \mathrm{y}$ facility (For these data, $100 \%$ of the dose to the MEI is allocated to volatile radionuclides.)

\begin{tabular}{|c|c|c|c|c|c|}
\hline \multirow[b]{2}{*}{$\begin{array}{c}\text { Burn-up } \\
(\text { GWd/tIHM) }\end{array}$} & \multirow{2}{*}{$\begin{array}{c}\text { Most Restrictive Dose Limit } \\
\text { (25 mrem/y Whole Body; } \\
75 \mathrm{mrem} / \mathrm{y} \text { Thyroid) }\end{array}$} & \multicolumn{4}{|c|}{ Required DF to Meet Dose Limit } \\
\hline & & ${ }^{3} \mathbf{H}^{\mathrm{a}}$ & ${ }^{14} \mathrm{C}$ & ${ }^{85} \mathbf{K r}^{\mathbf{a}}$ & ${ }^{129} \mathbf{I}$ \\
\hline 20 & Whole Body & $4.25-1$ & 1 & $4.15-1$ & 279 \\
\hline 30 & Whole Body & $7.55-1$ & 1 & $4.01-1$ & 273 \\
\hline 60 & Thyroid & $24.3-1$ & 1 & $3.62-1$ & 510 \\
\hline 100 & thyroid & $160-1$ & 1 & $3.21-1$ & 630 \\
\hline
\end{tabular}

${ }^{a}$ These are ranges depending on the fuel burn-up, i.e., $3.85-1$ is the range from 3.85 to 1 .

Table 14. A summary of DF requirements for the processing of PWR MOX in a $1000 \mathrm{t} / \mathrm{y}$ facility For these data, $10 \%$ of the dose to the MEI is allocated to volatile radionuclides

\begin{tabular}{|c|c|c|c|c|c|}
\hline \multirow[b]{2}{*}{$\begin{array}{c}\text { Burn-up } \\
\text { (GWd/tIHM) }\end{array}$} & \multirow{2}{*}{$\begin{array}{c}\text { Most Restrictive Dose Limit } \\
\text { (2.5 mrem/y Whole Body; } \\
7.5 \mathrm{mrem} / \mathrm{y} \text { Thyroid) }\end{array}$} & \multicolumn{4}{|c|}{ Required DF to Meet Dose Limit } \\
\hline & & ${ }^{3} \mathbf{H}^{\mathrm{a}}$ & ${ }^{14} \mathrm{C}$ & ${ }^{85} \mathrm{Kr}^{\mathrm{a}}$ & ${ }^{129} \mathrm{I}$ \\
\hline 20 & Whole Body & $158-1$ & 1 & $4.15-1$ & 2792 \\
\hline 30 & Thyroid & $193-1$ & 3 & $4.01-1$ & 2800 \\
\hline 60 & Thyroid & $490-1$ & 10 & $8.24-1$ & 5100 \\
\hline 100 & Thyroid & $720-1$ & 15 & $12.83-1$ & 8000 \\
\hline
\end{tabular}

\footnotetext{
${ }^{\mathrm{a}}$ These are ranges depending on the fuel burn-up, i.e., $3.85-1$ is the range from 3.85 to 1 .
} 


\subsection{Summary of Results for AHTGRs (PBR Design)}

Tables 15 and 16 summarize the DF requirements for the capture of the volatile radionuclides for AHTGR UOX (PBR) fuel with burn-ups ranging from 20 to $100 \mathrm{GWd}$ /tIHM. This assumes a nominal plant throughput of $1000 \mathrm{t} / \mathrm{y}$. Table 15 considers the case where the dose to the MEI only is attributable to the volatile radionuclides. This provides the smallest DF that would be required, based on the assumptions and inputs to the CAP-88 air dispersion and dose model. (Again note that no engineering margins are included in these values.) For only the lowest burn-up fuel $(20 \mathrm{GWd} / \mathrm{tIHM})$ is the dose to the whole body the limiting dose factor. For higher fuel burn-up, the thyroid dose is the limiting case. Controls for ${ }^{3} \mathrm{H}$ and ${ }^{85} \mathrm{Kr}$ are required for shorter cooled fuels, up to $\sim 80 \mathrm{y}$ cooling. No controls are required on ${ }^{14} \mathrm{C}$, except for very high burn-up fuels $(100 \mathrm{GWd} / \mathrm{tIHM})$. This need for ${ }^{14} \mathrm{C}$ control comes from the increase in ${ }^{14} \mathrm{C}$ that arises from the TRISO pebble coating as discussed in Section 2.5.1. It is worth noting that while no controls are applied for ${ }^{14} \mathrm{C}$ except for the $100 \mathrm{GWd} / \mathrm{tIHM}$ case, the increased amounts of ${ }^{14} \mathrm{C}$ result in the need for a higher DF for one of the other volatile radionuclides - in this case, ${ }^{3} \mathrm{H}$. Iodine DFs ranging from 158 to 653 , depending on fuel burn-up, would be required for any fuel cooling time.

The results shown in Table 16 come from an allocation of $10 \%$ of the dose limit being attributed to the volatile radionuclides. For all fuel burn-up cases the dose to the thyroid is the controlling limit. Iodine DFs range from 1577 to 6545, depending on fuel burn-up, for all cooling times. Iodine DF increases with fuel burn-up. Because of the higher level of ${ }^{14} \mathrm{C}$ in the fuel, there is a need to control its release for all cooling times and for all fuel burn-ups. Depending on the burn-up of the fuel and fuel age, additional controls are required for the other two volatile radionuclides. For short fuel cooling times, more controls are required, and the higher DFs are associated with these shorter-cooled fuels.

Table 15. A summary of DF requirements for the processing of AHTGR UOX in a 1000 t/y facility (For these data, $100 \%$ of the dose to the MEI is allocated to volatile radionuclides.)

\begin{tabular}{|c|l|c|c|c|c|}
\hline & Most Restrictive Dose Limit & \multicolumn{4}{|c|}{ Required DF to Meet Dose Limit } \\
\cline { 3 - 6 } $\begin{array}{c}\text { Burn-up } \\
\text { (GWd/tIHM) }\end{array}$ & \multicolumn{1}{|c|}{\begin{tabular}{c} 
75 mrem/y Whole Body; \\
\cline { 3 - 6 }
\end{tabular}} & ${ }^{\mathbf{3}} \mathbf{H}^{\mathbf{a}}$ & ${ }^{\mathbf{1 4}} \mathbf{C}$ & ${ }^{\mathbf{8 5}} \mathbf{K r}^{\mathbf{a}}$ & ${ }^{\mathbf{1 2 9}} \mathbf{I}$ \\
\hline 20 & Whole Body & $7.30-1$ & 1 & $9.13-1$ & 158 \\
\hline 30 & Thyroid & $12.4-1$ & 1 & $8.59-1$ & 189 \\
\hline 60 & Thyroid & $91-1$ & 1 & $7.33-1$ & 390 \\
\hline 100 & Thyroid & $41.4-1$ & 4 & $6.12-1$ & 653 \\
\hline
\end{tabular}

${ }^{\mathrm{a}}$ These are ranges depending on the fuel burn-up, i.e., $3.85-1$ is the range from 3.85 to 1 .

Table 16. A summary of DF requirements for the processing of AHTGR UOX in a $1000 \mathrm{t} / \mathrm{y}$ facility

(For these data, $10 \%$ of the dose to the MEI is allocated to volatile radionuclides.)

\begin{tabular}{|c|c|c|c|c|c|}
\hline \multirow[b]{2}{*}{$\begin{array}{c}\text { Burn-up } \\
\text { (GWd/tIHM) }\end{array}$} & \multirow{2}{*}{$\begin{array}{c}\text { Most Restrictive Dose Limit } \\
\text { (25 mrem/y Whole Body; } \\
75 \mathrm{mrem} / \mathrm{y} \text { Thyroid) }\end{array}$} & \multicolumn{4}{|c|}{ Required DF to Meet Dose Limit } \\
\hline & & ${ }^{3} \mathbf{H}^{\mathrm{a}}$ & ${ }^{14} \mathrm{C}$ & ${ }^{85} \mathbf{K r}^{\mathbf{a}}$ & ${ }^{129} \mathbf{I}$ \\
\hline 20 & Whole Body & $151-1$ & 5 & $9.13-1$ & 1577 \\
\hline 30 & Thyroid & $251-1$ & 10 & $8.59-1$ & 1714 \\
\hline 60 & Thyroid & $500-1$ & 20 & $22.0-1$ & 3650 \\
\hline 100 & Thyroid & $585-1$ & 30 & $61.25-1$ & 6545 \\
\hline
\end{tabular}

${ }^{\mathrm{a}}$ These are ranges depending on the fuel burn-up, i.e., $3.85-1$ is the range from 3.85 to 1 . 


\section{SENSITIVITY ANALYSIS}

Many factors can affect the doses to an MEI from radionuclide emissions from a used fuel reprocessing facility. The results of this study are constrained by the parameters in the CAP- 88 dispersion model. Many of the parameters in the CAP- 88 model can be user-specified, with the intent that this model can be used to evaluate ambient air concentrations and dose impacts for specific sites and facilities. Without sitespecific parameters for a specific fuel cycle and used fuel reprocessing facility, we have chosen hypothetical parameters as model inputs and conditions to create several illustrative examples of dose impacts from uncontrolled emissions of gaseous radionuclides in used fuel reprocessed in a hypothetical reprocessing facility. Results of these examples are only valid for the hypothetical input conditions. We have also performed various sensitivity studies to evaluate how variations in certain key input conditions can affect the hypothetical cases. These sensitivity studies and their results are summarized below.

\subsection{Radionuclide Input Rate}

The mass input rate of a radionuclide depends on the used fuel composition, which is defined by the fuel cycle, the fuel burn-up in the reactor, and the age of the used fuel after reactor discharge prior to reprocessing. Transmutation Library (Piet et al. 2011) data analyzed for used fuel compositions has shown that the amounts of the gaseous fission products that could be formed as daughters of the decay of other radionuclides are negligible compared to the amounts of those radionuclides in the used fuel at the time of reactor discharge. Furthermore, even though the decay of the gaseous fission products can result in progeny that has dose impacts that could be attributed to the parent radionuclides, progeny is not included in the gaseous fission product decay calculations. This is because progeny of the gaseous fission product decay that is not a gaseous fission product would be controlled during used fuel reprocessing as liquid, solid, or particulate matter, and so is not considered in this study.

The CAP88 dose results for a radionuclide are proportional to that radionuclide input rate. Similarly, as long as other parameters are unchanged:

- For a specific used fuel, the CAP-88 dose results are proportional to the amounts of radionuclides in the used fuel as the used fuel ages after reactor discharge prior to reprocessing.

- The CAP-88 dose results are proportional to the amounts of radionuclides in used fuel that vary as a function of fuel burn-up in the reactor.

- The CAP-88 dose results are proportional to the amounts of radionuclides in different used fuels from different fuel cycles or that have different ages or burn-ups.

- The CAP-88 dose results are proportional to the used fuel processing rate in the reprocessing facility.

\subsection{Stack Gas Height}

The stack is normally used to elevate the off-gas emission well above ground level and the heights of nearby structures, which aids in dispersing the plume. The higher the stack, the higher the plume begins; the point downwind at which the dispersed plume "hits" the ground increases, and so does the dilution of the stack gas, which results in lower ambient air concentrations and lower doses to the MEI. 
Table 17 shows that doubling the stack height from the $37 \mathrm{~m}(120 \mathrm{ft})$ used in the calculations in this study to $74 \mathrm{~m}$ decreases the dose of gaseous species $\left({ }^{3} \mathrm{H},{ }^{14} \mathrm{C}\right.$, and $\left.{ }^{85} \mathrm{Kr}\right)$ by over two-thirds and the dose from particulate-phase ${ }^{129} \mathrm{I}$ by almost one-half.

Table 17. Impact of a change in stack height from $37 \mathrm{~m}$ to $74 \mathrm{~m}$ on dose

\begin{tabular}{|c|c|}
\hline Radionuclide & Change (\%) \\
\hline${ }^{3} \mathrm{H}$ & -69 \\
\hline${ }^{14} \mathrm{C}$ & -69 \\
\hline${ }^{85} \mathrm{Kr}$ & -70 \\
\hline${ }^{129} \mathrm{I}^{\mathrm{a}}$ & -45 \\
\hline
\end{tabular}

${ }^{\text {a }}$ Particulate form $100 \%$

\subsection{Stack Gas Exit Velocity and Radionuclide Concentration}

The CAP-88 model allows a user to assume that the rise, if any, of a plume of off-gas leaving the stack is either momentum-dominated or buoyancy-dominated. The momentum is provided by the stack gas exit velocity. The higher the exit velocity, the higher the plume rises as it disperses in the atmosphere, and so (a) the distance at which the plume reaches ground-level increases, and (b) the concentration at the point where the plume reaches the ground is more dilute because of increased dispersion. These factors combine to reduce the dose to the MEI.

Table 18 shows the results from CAP-88 calculations when the stack gas velocity is varied between 9 and $36 \mathrm{~m}^{3} / \mathrm{s}$ by varying the flow rate of stack gas without changing the radionuclide input rate. In this case, two parameters change: the stack gas velocity and the radionuclide concentration in the stack gas. When the nominal $18 \mathrm{~m} / \mathrm{s}$ stack gas velocity is reduced to half its nominal value and the stack gas radionuclide concentration is increased to twice its nominal concentration, then the total dose increases by $21 \%$. When the nominal $18 \mathrm{~m} / \mathrm{s}$ stack gas velocity is doubled (and the stack gas radionuclide concentration is decreased to half its nominal value), then the total dose decreases by $29 \%$.

The individual doses from each of the gaseous fission products vary by nearly identical amounts (slightly less ${ }^{85} \mathrm{Kr}$, perhaps because of its inertness, which may dominate the dose conversion more significantly than for the other radionuclides that would play more active roles in the biosphere). The total dose tracks very close to the dose from ${ }^{129} \mathrm{I}$ because, when the form of the ${ }^{129} \mathrm{I}$ is particulate (as in this case), then the dose from ${ }^{129} \mathrm{I}$ is large compared to the other doses from the other radionuclides (see Section 3.7.2) and so dominates the total dose. But regardless of gaseous phase, particulate phase, or chemical inertness, the differences in the change in dose between the different radionuclides is less than $10 \%$ of the change in the dose.

Table 19 shows how the dose changes when only the stack gas exit velocity is changed. The exit gas velocity is changed, while the stack gas flow rate and concentrations of radionuclides are held constant, by varying the stack inside diameter (ID). 
Table 18. Impact of stack gas exit velocity and radionuclide concentration on dose

\begin{tabular}{|c|c|c|c|}
\hline $\begin{array}{r}\text { Stack velocity, } \mathbf{m} / \mathbf{s} \\
\text { Location of MEI, } \mathbf{m}\end{array}$ & 9 & 18 & 36 \\
& 600 ENE & 600 ENE & 700 ENE \\
\hline & 20 & - & -29 \\
\hline${ }^{3} \mathbf{H}$ & 21 & - & -29 \\
${ }^{14} \mathbf{C}$ & 19 & - & -26 \\
${ }^{85} \mathbf{K r}$ & 21 & - & -29 \\
${ }^{129} \mathbf{I}$ & $\mathbf{2 1}$ & - & $\mathbf{- 2 9}$ \\
\hline
\end{tabular}

Notes:

1. Baseline $=18 \mathrm{~m} / \mathrm{s}$.

2. Constant input radionuclide rate; constant stack diameter $(1.5 \mathrm{~m})$.

3. Dose values are for a hypothetical facility in the northwestern United States.

Table 19. Impact of stack gas exit velocity on dose

\begin{tabular}{|r|c|c|c|}
\hline Stack velocity, $\mathbf{~ m} / \mathbf{s}$ & 9 & 18 & 36 \\
\hline Stack diameter, $\mathbf{m}$ & 2.12 & 1.5 & 1.06 \\
\hline Location of MEI, $\mathbf{m}$ & $600 \mathrm{ENE}$ & $600 \mathrm{ENE}$ & $700 \mathrm{ENE}$ \\
\hline \multirow{3}{|c|}{ Change, $\%$} \\
\hline${ }^{3} \mathbf{H}$ & 11 & - & -13 \\
${ }^{14} \mathbf{C}$ & 12 & - & -13 \\
${ }^{\mathbf{8 5}} \mathbf{K r}$ & 11 & - & -12 \\
${ }^{129} \mathbf{I}$ & 12 & - & -14 \\
Total dose & $\mathbf{1 2}$ & - & $\mathbf{- 1 3}$ \\
\hline
\end{tabular}

Notes:

1. Baseline condition $=18 \mathrm{~m}$.

2. Constant input radionuclide rate; varying stack ID.

3. Dose values are for a hypothetical facility in the northwestern United States.

The percent change in dose is less in this case because the impact on dose from changing the radionuclide concentration in the stack gas is eliminated. The change in dose from changing the exit gas velocity is about half the change in dose caused by the combined change in exit gas velocity and radionuclide concentration in the stack gas.

\subsection{Stack Gas Buoyancy}

The CAP-88 user can specify if a plume of gas leaving the stack is either momentum-dominated or buoyancy-dominated. If the stack gas is buoyancy-dominated, then the density of the plume, relative to the density of the atmosphere, determines plume rise as the plume disperses. The model accounts for density change by allowing the user to input the difference in enthalpy of the stack gas compared to the enthalpy of the atmosphere. By considering the enthalpy of the stack gas, the differences in both the temperature and the molecular weight between the stack gas and the atmosphere are taken into account. 
Table 20 shows how, for a stack gas that has constant average molecular weight, the dose changes for different stack gas temperatures compared to the ambient atmospheric temperature. Compared to a nominal differential temperature of $5{ }^{\circ} \mathrm{C}$, increases in the differential temperature of up to $25^{\circ} \mathrm{C}$ decrease the dose by $55 \%$. This change in dose, when normalized to percent change in the input parameter, is about four times larger than the changes in dose caused by either changes in stack gas momentum (velocity) or stack gas radionuclide concentration.

Table 20. Impact of stack gas density difference compared to the atmosphere relative to the case of $\Delta \mathrm{T}=5^{\circ} \mathrm{C}$ on dose

\begin{tabular}{|c|c|c|c|c|}
\hline Heat emission rate, $\mathrm{kJ} / \mathrm{s}$ & 214.2 & 428.3 & 857.0 & 1071 \\
\hline Temperature difference, ${ }^{\circ} \mathrm{C}$ & 5 & 10 & 20 & 25 \\
\hline \multirow[t]{2}{*}{ Location of MEI, $\mathrm{m}$} & $800 \mathrm{ENE}$ & $900 \mathrm{ENE}$ & $1000 \mathrm{ENE}$ & $1000 \mathrm{ENE}$ \\
\hline & \multicolumn{4}{|c|}{ Dose Change, \% } \\
\hline${ }^{3} \mathrm{H}$ & - & $-16 \%$ & $-38 \%$ & $-54 \%$ \\
\hline${ }^{14} \mathrm{C}$ & - & $-16 \%$ & $-39 \%$ & $-55 \%$ \\
\hline${ }^{85} \mathrm{Kr}$ & - & $-15 \%$ & $-35 \%$ & $-49 \%$ \\
\hline${ }^{129} \mathrm{I}$ & - & $-16 \%$ & $-38 \%$ & $-55 \%$ \\
\hline Total & - & $-16 \%$ & $-38 \%$ & $-55 \%$ \\
\hline
\end{tabular}

Notes:

1. The volumetric stack gas flowrate is $33.6 \mathrm{~m}^{3} / \mathrm{s}$ (71 $\left.200 \mathrm{scfm}\right)$.

2. The stack gas has an average molecular weight and heat capacity equivalent to air.

This change in dose could also occur if the density decreased by $6.8 \%$ from a lower average molecular weight (assuming that the temperature stays constant). Such a change in density might occur, for example, if the stack gas moisture content significantly increased, although that might have other impacts on the dose of ${ }^{3} \mathrm{H}$ if the larger amount of moisture significantly condensed into droplets.

\subsection{Location of U.S. Reprocessing Facility}

The CAP-88 cases in this study unavoidably use specific meteorological data (wind history, average ambient temperature, annual precipitation, and average humidity) to perform the air dispersion calculations. We have used generic meteorological data to illustrate the changes that take place if the same facility is located in four geographical areas in the United States.

Table 21 shows how gaseous radionuclide dose can vary for four representative U.S. locations. These generic locations are the Northwest, Southwest, Central Southeast, and Southeast. This selection also covers a range of wind history, ambient temperature, precipitation, and humidity. The dose variations in Table 21 are from multiple factors. Areas with higher winds or directions that vary significantly reduce dose because there is more air dispersion. Areas with higher precipitation result in more rapid deposition of especially ${ }^{14} \mathrm{C}$ and ${ }^{129} \mathrm{I}$, which can cause higher dose rates for these radionuclides. Areas with higher humidity result in isotopic dilution of ${ }^{3} \mathrm{H}$, reducing the dose. Results from the CAP- 88 studies with meteorology from these few selected locations indicate that, depending on location in the US:

- Dose from ${ }^{3} \mathrm{H}$ can vary by a factor of 2 or more, depending on the humidity.

- Dose from ${ }^{14} \mathrm{C}$ and ${ }^{129} \mathrm{I}$ may be increased by $10 \%$ or more in areas with higher precipitation.

- Dose from any of the radionuclides can vary by $20 \%$ or more from wind direction variation and velocity. 
Table 21. Impact of U.S. location of facility on dose relative to the base case of the northwestern United States

\begin{tabular}{|c|c|c|c|c|}
\hline & Northwest & Southeast & Central SE & Southwest \\
\hline Meteorological conditions & & & & \\
\hline Avg Temperature, ${ }^{\circ} \mathrm{C}$ & 6.77 & 17.81 & 13.1 & 11 \\
\hline Annual Precipitation, $\mathrm{m}$ & 0.194 & 1.14 & 1.35 & 0.391 \\
\hline Avg Humidity, $\times 10^{3} \mathrm{~kg} / \mathrm{m}^{3}$ & 3.6 & 12 & 8.9 & 8.0 \\
\hline Location of MEI from stack, m & 600 & 500 & 500 & 400 \\
\hline Wind Direction & ENE & $\mathrm{S}$ & $\mathrm{NE}$ & $\mathrm{NE}$ \\
\hline \multicolumn{5}{|c|}{ Dose Change (\%) } \\
\hline & - & -58 & -43 & -50 \\
${ }^{3} \mathrm{H}$ & - & 15 & 23 & 0 \\
${ }^{14} \mathrm{C}$ & - & 8 & 20 & 2 \\
${ }^{85} \mathrm{Kr}$ & - & 27 & 37 & 1 \\
\hline${ }^{129} \mathrm{I}$ & \multicolumn{5}{|c}{} \\
\hline
\end{tabular}

Note: The assumed form of ${ }^{129} \mathrm{I}$ in these studies was particulate.

These values may vary for other locations in the country.

\subsection{Lid Height}

One of the inputs required by the CAP-88 simulation is the "height of lid" under the meteorological data tab. This term refers to the average height of the tropospheric mixing layer, or the atmospheric boundary layer, at the site. Within this layer there is active transport and mixing of gases, vapors, and aerosols from convection caused, or influenced, by temperature variations, wind velocity, and structures on the ground's surface. The actual mixing height varies during a typical day, with the height being lower during calm morning and evening hours and higher during the afternoon. The default value in CAP- 88 is set for $1000 \mathrm{~m}$. This value was used in the calculations of this study. In past studies, the INL Applied Geosciences department recommended 800 m (Staley et al. 2004), while at Los Alamos a value of $1525 \mathrm{~m}$ was used (Jacobson 1997).

A set of runs was conducted with the baseline case with the "height of lid" varied between runs. From 100 to $10,000 \mathrm{~m}$ (largest value used), the lid height had no effect on the dose or location of an MEI. However, for a lid height of $50 \mathrm{~m}$, the dose to an MEI increased from 1.35 to $1.67 \mathrm{mrem} / \mathrm{y}$, and the location was moved from 600 to $500 \mathrm{~m}$ with a slightly different compass position for the MEI.

If the lid height becomes less than about twice the stack height (for the conditions in the sensitivity study), then lid height starts to cause the dose to increase by reducing mixing.

\subsection{Agricultural Data}

The CAP-88 model (Rosnick 1992) includes as part of the calculation the dose to the MEI through ingestion with user-selected food sources. These cases determine the fraction, if any, of vegetables, milk, and meat that are consumed, are home-produced, come from the area impacted by the assessment area, or are imported from outside the assessment area. The user can select among several cases (urban, rural, local, regional, or imported) or may manually enter specific choices for those fractions. 
Table 22 shows how the dose is impacted by choosing rural versus urban food sources. This table shows that in the rural scenario, most of the vegetables and some of the milk and meat are home-produced; the remainder comes from the assessment area, and none is imported. In the urban scenario, none or almost none of the vegetables, milk, or meat is home-produced; nearly all of the food is from the assessment area, and none is imported. When the majority of the food is not home-produced by the MEI, but still from the assessment area, then the dose for the radionuclides that are incorporated into the food cycle is decreased by about a factor of 0.33 . The dose from ${ }^{85} \mathrm{Kr}$ remains unchanged because it does not play a role in the food cycle.

Table 22. The impact of urban and rural food sources on dose (The changes are relative to the rural case.)

\begin{tabular}{|c|c|c|c|c|c|c|}
\hline \multirow[b]{2}{*}{ Source } & \multicolumn{3}{|c|}{ Rural } & \multicolumn{3}{|c|}{ Urban } \\
\hline & Vegetable & Milk & Meat & Vegetable & Milk & Meat \\
\hline Fraction home produced & 0.7 & 0.40 & 0.44 & 0.076 & 0 & 0.008 \\
\hline Fraction from assessment area & 0.3 & 0.60 & 0.56 & 0.92 & 1 & 0.99 \\
\hline Fraction imported & 0 & 0 & 0 & 0 & 0 & 0 \\
\hline Total & 1 & 1 & 1 & 1 & 1 & 1 \\
\hline \multicolumn{7}{|c|}{ Change (\%) } \\
\hline${ }^{3} \mathrm{H}$ & \multicolumn{3}{|c|}{-} & \multicolumn{3}{|c|}{-28} \\
\hline${ }^{14} \mathrm{C}$ & \multicolumn{3}{|c|}{-} & \multicolumn{3}{|c|}{-39} \\
\hline${ }^{85} \mathrm{Kr}$ & \multicolumn{3}{|c|}{-} & \multicolumn{3}{|c|}{0} \\
\hline${ }^{129} \mathrm{I}$ & \multicolumn{3}{|c|}{-} & \multicolumn{3}{|c|}{-38} \\
\hline
\end{tabular}

Notes: This sensitivity study was done for the humid Southeast facility location.

\subsection{Dose Sensitivity to the Chemical/Physical Form of ${ }^{129}$ I}

The chemical form of ${ }^{129}$ I plays an important role in the dose the MEI receives from a given amount of ${ }^{129} \mathrm{I}$.

\subsubsection{Chemical/physical form of ${ }^{129}$ I}

Iodine released from the exhaust stack of a processing facility may exist in several different chemical species including elemental iodine $\left(\mathrm{I}_{2}\right)$, hydrogen iodide $(\mathrm{HI})$, hypoiodous acid (HOI), and organic iodine (methyl iodide $\left[\mathrm{CH}_{3} \mathrm{I}\right]$ is typically used as a surrogate). CAP88 allows the user to enter inorganic iodine as either a particulate or vapor, while methyl iodide defaults to a gas. The choice of speciation and form can have a huge impact on the calculated dose. In several baseline runs the estimated dose varied by 3 orders of magnitude, with the particulate form delivering the largest dose to an exposed individual, while the gas and vapor forms delivered much smaller and similar doses.

The speciation and behavior of iodine released to the atmosphere is not easily determined, but all forms are of considerable interest since they all may enter inhalation and ingestion pathways as described by the IAEA (IAEA 1973):

Iodine isotopes may be discharged to the atmosphere as molecular iodine or as inorganic or organic iodides, depending upon their origin and the conditions prevailing in the system. Molecular iodine may become adsorbed on submicron particles during or after discharge to atmosphere. All forms are subject to dispersion in the atmosphere by natural 
processes of turbulence, convection due to solar and other heating, movement by the wind, etc., and usually do not deposit under the influence of gravity. They are, however, deposited on the ground and other surfaces such as pasture grass, at rates which depend upon such variables as the physical and chemical form of the iodine and weather conditions, including wind speed and rainfall rates.

Information from reprocessing plants indicates a significant variation in major release points for iodine. At the Idaho reprocessing plant, only about $5 \%$ of iodine entering in the fuel was released to the dissolver off-gas. The remaining iodine inventory was carried downstream where thermal processing of waste effluents resulted in as much as $87 \%$ being driven off at the calciner. ${ }^{a}$ The balance of iodine was retained in the solid calcine product $(\sim 1 \%)$ and in the liquid from an evaporator associated with the process. The speciation of iodine in the off-gas from the calciner and released (after filtration through HEPA filters and sorption on silica gel) to the stack was estimated to be $15 \% \mathrm{I}_{2}, 21 \% \mathrm{HOI}$, and $64 \%$ organic iodine (McManus et al. 1982). By comparison, at the Karlsruhe Reprocessing Plant (WAK) in Karlsruhe, Germany, as much as $99 \%$ of the iodine was released from the dissolver, where the practice of fumeless dissolution $^{\mathrm{b}}$ was used. Atmospheric iodine sampling around the WAK was performed over two time periods (Table 23) (Wershofen and Aumann 1989). The sampling procedure separated the iodine into three fractions: iodine associated with aerosol particles, inorganic gases, and organic gases.

Table 23. Atmospheric iodine speciation in the vicinity of the WAK

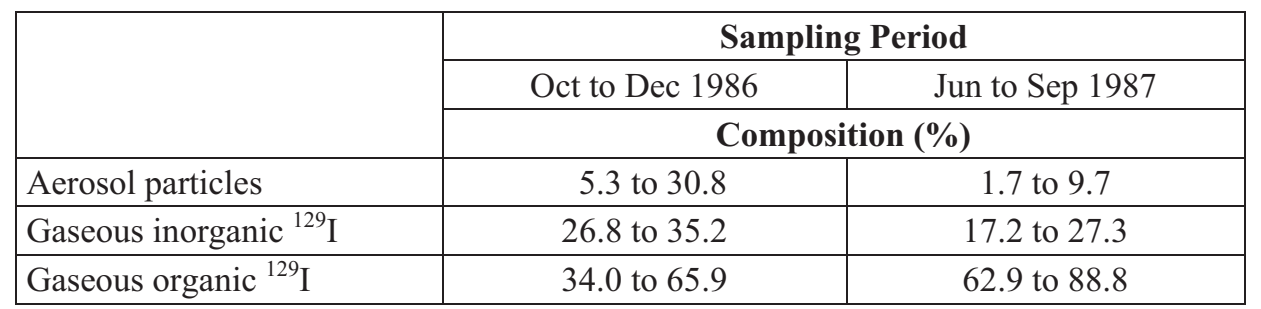

The information presented in Table 23 is significant in that the reprocessing plants at Idaho and Karlsruhe had similar emissions (primarily organic iodine) even though the major release points were from different unit operations. The sampling near the WAK plant indicates that particulate iodine is a small, but significant, fraction of the inventory. The implications of these data are that the iodine specified in the CAP-88 simulation could be apportioned between the organic (as methyl iodide vapor), inorganic (gas), and particulate forms. In doing so, the estimated dose for uncontrolled release would be reduced from that estimated assuming all particulate (the most conservative approach) release. The consequent DF required for emission compliance could also be reduced.

\subsubsection{Sensitivity results from CAP-88 calculations}

In CAP-88 (Rosnick 1992), the dose to the MEI depends strongly on the chemical form (particulate or gas) of the radionuclide of interest. For this report, we performed all of the ${ }^{129}$ I dose calculations assuming the iodine to be in particulate form, recognizing that this assumption results in conservatively high ${ }^{129} \mathrm{I}$ dose results.

\footnotetext{
${ }^{a}$ The calciner was a thermal treatment process that converted liquid waste to a solid granular form.

${ }^{\mathrm{b}}$ Fumeless dissolution involves adding oxygen to the dissolver slightly in excess of that required for complete NOx recombination.
} 
We also performed a sensitivity study where the chemical and physical forms of the iodine were varied. Of the isotopes ${ }^{3} \mathrm{H},{ }^{14} \mathrm{C},{ }^{85} \mathrm{Kr}$, and ${ }^{129} \mathrm{I}$, only iodine has options that include particulate. Since the other three are normally gaseous $\left({ }^{14} \mathrm{C}\right.$ as $\mathrm{CO}_{2}$ and ${ }^{85} \mathrm{Kr}$ ) and water vapor is the likely form in which ${ }^{3} \mathrm{H}$ appears, the sensitivity on the chemical form was determined only for ${ }^{129}$ I. In CAP88 (Rosnick 1992), there are three options for iodine - particulate, vapor, and organic. A single case serves to illustrate the salient factor for iodine. For ${ }^{129} \mathrm{I}$, we considered the case for $0.0482 \mathrm{mCi}$ emitted from a processing facility located in Northwest. The prevailing winds and temperature conditions led to the maximum dose being deposited at $700 \mathrm{~m}$ northeast from the stack. The results for four cases of chemical form distribution are shown in Table 24.

Table 24. Results of the sensitivity study on the distribution of dose from $0.00482 \mathrm{mCi}$ of ${ }^{129} \mathrm{I}$ in different chemical forms to the MEI located $700 \mathrm{~m}$ from the stack of a reprocessing plant hypothetically located in the Northwest

\begin{tabular}{|c|c|c|c|c|c|c|c|}
\hline \multirow{2}{*}{\multicolumn{3}{|c|}{ Chemical/Physical Form (\%) }} & \multicolumn{5}{|c|}{ Dose Contributions (mrem/y) } \\
\hline & & & \multicolumn{3}{|c|}{ Whole Body } & \multirow[b]{2}{*}{ Total } & \multirow{2}{*}{$\begin{array}{c}\text { Organ, } \\
\text { Thyroid }\end{array}$} \\
\hline Particulate & Vapor & Organic & Particulate & Vapor & Organic & & \\
\hline 100 & 0 & 0 & 1.5 & & & 1.5 & 30.2 \\
\hline 50 & 50 & 0 & 0.75 & 0.0019 & & 0.76 & 15.1 \\
\hline 30 & 30 & 40 & 0.45 & 0.0012 & 0.0012 & 0.46 & 9.1 \\
\hline 0 & 50 & 50 & 0 & 0.0019 & 0.0015 & 0.0034 & 0.069 \\
\hline
\end{tabular}

These results show that the dose to the MEI scales with the fraction of emitted ${ }^{129}$ I that is classified as particulate. The dose calculated when assuming the $100 \%$ particulate form was on the order of $10^{3}$ times higher for both the whole body and thyroid, compared to when the iodine form was assumed to be $50 \%$ vapor and $50 \%$ organic. In cases where only $\sim 30 \%$ to $\sim 70 \%$ of the total iodine is in particulate form (as indicated by the Karlsruhe Reprocessing Plant shown in the above table), then the dose-based ${ }^{129}$ I DFs estimated in this report could be reduced to about a third to two-thirds the reported values-a reduction between $30 \%$ to $3 \times$. Since the dose values scale with the amount of particulate and since studies performed have yielded reliable estimates of the distribution in a typical emission from a reprocessing facility stack, the doses from ${ }^{129}$ I can easily be scaled to that fraction, because the contributions from the vapor and organic are about a factor of 100 less. The same can be concluded for the dose to the thyroid (Table 24).

\section{CONCLUSIONS}

As a result of fuel reprocessing, volatile radionuclides may be released from the facility stack if no processes are put in place to remove them. The radionuclide of primary concern in this paper is ${ }^{129} \mathrm{I}$, but we also considered the impacts of the releases of ${ }^{3} \mathrm{H},{ }^{14} \mathrm{C}$, and ${ }^{85} \mathrm{Kr}$. The question we attempted to answer is how efficient must the removal process be? To answer this question, we examined the three regulations that may impact the degree to which these radionuclides must be reduced before process gases can be released from the facility. These regulations are 40 CFR 61 (EPA 2010a), 40 CFR 190 (EPA 2010b), and 10 CFR 20 (NRC 2012). These regulations apply to the total radonuclide release and to a particular organ, the thyroid. Because these doses can be divided among all the radionuclides in different ways and even within the four volatile radionuclides, we examined several cases. We first looked at the inventories for these radionuclides for three fuel types (PWR UOX, PWR MOX, and AHTGR), several burn-up values, and time out of reactor extending to $200 \mathrm{y}$. We calculated doses to the maximum exposed individual (MEI) with the EPA code CAP-88 (Rosnick 1992). Finally, we looked at two dose cases. Allowing all of the allowable dose to be used by the volatile radionuclides is one case but perhaps is unrealistic. In lieu of 
this, we arbitrarily selected a value of $10 \%$ of the allowable dose to be assigned to the volatile radionuclides. We calculated the required DFs for both of these cases, including the case for the thyroid dose for which ${ }^{14} \mathrm{C}$ and ${ }^{129} \mathrm{I}$ were the main contributors. With respect to ${ }^{129} \mathrm{I}$ doses, we found that the highest dose was calculated with iodine as a fine particulate. The dose scaled as the fraction of the total ${ }^{129}$ I that was particulate. Therefore, we assumed for all of our calculations that $100 \%$ of the ${ }^{129}$ I was particulate and allow the user of the results given here to scale our calculated doses to their needs.

To summarize the data given in this paper, we present the data for the maximum DFs required to meet regulations shown in Table 25. The DFs shown in this table contain no engineering margin and could vary by a factor of 2 or more if different site-specific or reprocessing-facility-specific assumptions are used. In terms of establishing practicable target DFs for the capture processes under development, we believe that these should be on the order of 3 to 5 times the values shown under the $10 \%$ dose allocation columns in Table 25. These DFs are within the range of DFs that are reported for the capture technologies for the volatile radionuclides (Gombert 2007). Achieving the required iodine and tritium DFs will be the more challenging. While it can be argued that the $10 \%$ dose allocation was selected arbitrarily, and it was, the full dose allocation is certainly too optimistic as other radionuclides will contribute to the total dose. The anticipated range is expected to be from 5\% to 50\%. Further analysis into how potential emissions of other radionuclides in a used fuel can be controlled would be required to refine this value.

It should also be evident from the discussions in Section 2.8 that it possible to decrease the DF for one volatile radionuclide and increase the DF for one of the others and still maintain the same dose to the MEI. With this in mind it is not possible to arrive at a single target DF. The DFs required to limit the dose to the MEI are a function of the fuel age at the time of processing. This topic is the subject of a subsequent analysis.

Table 25. Maximum DFs required for the volatile radionuclides of concern in this report

\begin{tabular}{|l|c|c|c|c|c|c|}
\hline \multirow{2}{*}{} & \multicolumn{3}{|c|}{ Full Dose Allocation to Volatile Radionuclides } & \multicolumn{3}{c|}{ 10\% Dose Allocation to Volatile Radionuclides } \\
\cline { 2 - 7 } & PWR/UOX & PWR/MOX & AHTGR & PWR/UOX & PWR/MOX & AHTGR \\
\hline${ }^{3} \mathrm{H}$ & 25 & 160 & 42 & 600 & 720 & 585 \\
\hline${ }^{14} \mathrm{C}$ & 1 & 1 & 4 & 10 & 15 & 30 \\
\hline${ }^{85} \mathrm{Kr}$ & 9 & 4.2 & 9.2 & 18 & 13 & 62 \\
\hline${ }^{129} \mathrm{I}$ & 380 & 630 & 650 & 3800 & 8000 & 6550 \\
\hline
\end{tabular}

\section{REFERENCES}

Abbott et al. 1999. "Screening Level Risk Assessment for the New Waste Calcining Facility," INEEL/EXT-97-00686, Revision 5a, May.

AEC. 1954. The Atomic Energy Act of 1954, as Amended. Public Law 83-703. Atomic Energy Commission, Washington, DC.

ASTM. 2008. "ASTM C833-01, Standard Specification for Sintered Uranium-Plutonium Dioxide Pellets." American Society for Testing and Materials, West Conshohocken, PA.

ASTM. 2011. "ASTM C776-06, Standard Specification for Sintered Uranium Dioxide Pellets." American Society for Testing and Materials, West Conshohocken, PA. 
Collins, ED, RT Jubin, GD DelCul, BB Spencer, and JP Renier. 2009. Advanced Fuel Cycle Treatment, Recycling, and Disposal of Nuclear Waste. In Proceedings of Global 2009, 2595-602 pp. American Nuclear Society, LaGrange Park, IL.

DeHart, MD, and SM Bowman. 2011. "Reactor Physics Methods and Analysis Capabilities in SCALE." Nuclear Technology 174(2):196-213.

DelCul, GD, BB Spencer, and ED Collins. 2003. Fuel Cycle Advantages Resulting from the Significant Inventory of U.S. Spent Fuel. In Proceedings of Global 2003 International Conference, American Nuclear Society, La Grange Park, IL.

DOE. 2010. "Statement of Warren F. Miller, Jr., Assistant Secretary for Nuclear Energy, U.S. Department of Energy before the Committee on Science and Technology U.S. House of Representatives." US DOE, Washington, DC.

EPA. 1999. Cancer Risk Coefficients for Environmental Exposure to Radionuclides . Report No. EPA 402-R-99-001, Environmental Protection Agency, Washington, DC.

EPA. 2010a. Chapter 40. Environmental Protection Agency: Part 61--National Emission Standards for Hazardous Air Pollutants. Subpart H-National Emission Standards for Emissions of Radionuclides Other Than Radon from Department of Energy Facilities. 92 - Standard. 40CFR61.92. US Environmental Protection Agency, Washington, DC.

EPA. 2010b. Protection of Environment: Chapter I--Environmental Protection Agency (Continued). Part 190_Environmental Radiation Protection Standards for Nuclear Power Operations. 40 CFR 190.10. US Environmental Protection Agency, Washington, DC.

FRAMATOM. 2001. Fuel Qualification Plan. Report No. FRA-ANP 77-5005775-02, AREVA North America, Bethesda, MD.

Gauld, IC, G Radulescu, G Ilas, BD Murphy, ML Williams, and D Wiarda. 2011. "Isotopic Depletion and Decay Methods and Analysis Capabilities in SCALE." Nuclear Technology 174(2):169-95.

Gombert, D. 2007. Global Nuclear Energy Partnership Integrated Waste Management Strategy Waste Treatment Baseline Study - Volume I. GNEP-WAST-AI-RT-2007-000324, September (2011).

IAEA. 1973. Control of Iodine in the Nuclear Industry, Technical Report Series No. 148, International Atomic Energy Agency, Vienna (1973)

ICRP. 1995. Age-Dependent Doses to the Members of the Public from Intake of Radionuclides - Part 5 Compilation of Ingestion and Inhalation Coefficients. Report No. ICRP Publication 72, International Commission on Radiological Protection, Ottawa, Ontario, Canada.

Ilas, G, and IC Gauld. 2011. Source Term for High Burnup HTGR Fuel - Pebble Bed Design. Report No. ORNL/LTR-2011/20, Oak Ridge National Laboratory, Oak Ridge, TN.

Jacobson, KW. 1997. "U.S. Department of Energy Report, 1996 LANL Radionuclide Air Emissions," LA-13353-ENV, August (1997)

MacDonald, PE, JW Sterbentz, RL Sant, P Bayless, HD Gougar, RL Moore, AM Ougouag, and WK Terry. 2003. NGNP Point Design - Results of the Initial Neutronics and Thermal-Hydraulic Assessments 
During FY-03, Rev. 1. Report No. INEEL/EXT-03-00870, Idaho National Engineering and Environmental Laboratory, Idaho Falls, ID.

McManus, GJ, FA Duce, SJ Fernandez, and LP Murphy. 1982. “A Model of Iodine-129 Process Distributions in a Nuclear Fuel Reprocessing Plant," Exxon Nuclear Idaho Company, ENICO-1108, April.

NRC. 2012. Chapter 10, Energy: Part 20 - Standards for Protection against Radiation. 10 CFR 20. US Nuclear Regulatory Commission, Washington, DC.

ORNL. 2009. SCALE: A Modular Code System for Performing Standardized Computer Analyses for Licensing Evaluations (Version 6). Report No. ORNL/TM 2005/39 Vols. I - III, Oak Ridge National Laboratory, Oak Ridge, TN.

Piet, SJ, SE Bays, DW Gerts, and EA Hoffman. 2011. "Description of Transmutation Library for Fuel Cycle System Analyses (FY2011 Update)," FCRD-SYSA-2010-000116, Rev. 1, INL/EXT-10-19545, Rev. 1, September 16.

Rosnick, R. 1992. CAP-88 ( Clean Air Act Assessment Package-1988). US Environmental Protection Agency, Washington, DC.

Rosnick, R. 2007. CAP88-PC Version 3.0 User Guide. Environmental Protection Agency, Washington, DC.

Soelberg, N, M Abbott, DR Haefner, and RT Jubin. 2008. Gaseous Fission Product Emissions Control During Spent Nuclear Fuel Recycling. Presented at 235th ACS National Meeting and Exposition,

Staley, CS, ML Abbott, and PD Ritter. 2004. "INEEL Air Modeling Protocol," INEEL/EXT-04-02511, December (2004).

USA. 1974. Energy Reorganization Act of 1974. Public Law 93-438. US Senate and House of Representatives, Washington, DC.

Wershofen, H, and DC Aumann. 1989. "Iodine-129 in the environment of a nuclear fuel reprocessing plant: VII. Concentrations and chemical forms of ${ }^{129} \mathrm{I}$ and ${ }^{127} \mathrm{I}$ in the atmosphere," J. Environ. Radioact. 10(2): 141-156. 